\title{
WAGE INDEXATION AND INFLATION PERSISTENCE
}

\author{
Víctor López Pérez \\ CEMFI Working Paper No. 0303
}

January 2003

CEMFI

Casado del Alisal 5; 28014 Madrid

Tel. (34) 914290 551. Fax (34) 914291056

Internet: www.cemfi.es

I would like to thank Samuel Bantolila, Gunter Coenen, Jose Garcia-Solanes, Matt Klaeffling, Claudio Michelacci, Benoit Mojon, Rafael Repullo, Diego RodriguezPalenzuela, Frank Smets and seminar participants at CEMFI, ECB, the LACEA 2002 Annual Meeting and the Workshop on International Economics (University of Málaga, Spain) for their insightful commets. All remaining errors are mine. The views expressed are those of the author and do not necessarily represent those of the European Central Bank. 
CEMFI Working Paper No. 0303

January 2003

\title{
WAGE INDEXATION AND INFLATION PERSISTENCE
}

\begin{abstract}
This paper presents a model whose key feature is the existence of wage indexation clauses to lagged inflation. The main result that can be drawn is that the higher the proportion of labour contracts that include indexation clauses, the more important past inflation will be when explaining current inflation movements. However, a plausible (small) degree of indexation does not explain observed US inflation autocorrelations. Besides, optimal monetary policy is computed and the optimal degree of indexation is obtained. Finally, a twocountry configuration is presented and the losses incurred as a result of setting a common monetary policy are calculated.
\end{abstract}

JEL Codes: J30, E31, E52.

Keywords: Indexation clauses, degree of indexation, inflation inertia, optimal monetary policy rule.

Víctor López Pérez

ECB and CEMFI

Victor.Lopez@ecb.int 


\section{Introduction}

Inflation dynamics still remain a mystery. While theoretical models, starting with Taylor's staggered wage-setting model (Taylor (1979)), Rotemberg's cost-of-adjustment model (Rotemberg (1982)) and the staggered price-setting model developed by Calvo (1983), ${ }^{1}$ propose that current inflation rates depend on future expected inflation and on current and future expected measures of excess demand (what has been called the New Phillips Curve), empirical findings have shown that it is very difficult to reject the significant explanatory power of past inflation rates.

Gali and Gertler (1999) try to reconcile the New Phillips Curve with the data using a different variable (the labour share) to measure marginal costs instead of the previously used output gap. They found that this new specification, which is closer to the theoretical model, does a good job in explaining US inflation dynamics, but they still find it difficult to totally reject the hypothesis that past inflation causes current inflation ${ }^{2}$. In a recent but already well-known paper, Mankiw (2001) analyses the joint dynamics of unemployment and inflation. He suggests that current inflation must be dependent upon past inflation in order to reproduce plausible comovements of inflation and unemployment rates. Atkeson and Ohanian (2001) and Roberts (2001) come to the same conclusion. The latter remarks that the weight of lagged inflation could be around 60\%. Indeed, Gali (2000) argues that the New Phillips Curve fits the data better than is generally believed, although the task of explaining inflation persistence remains. ${ }^{3}$

Of course I am not the first person who has tried to deal with this prob-

\footnotetext{
${ }^{1}$ See the analysis made by Roberts (1995) of the similarities between the inflation implications of these models.

${ }^{2}$ Gali, Gertler and López-Salido (2001) and Gali and López-Salido (2001) obtain the same result for inflation in the euro area and Spain, respectively.

${ }^{3}$ Chari, Kehoe and McGrattan (2000) assert that staggered price-setting is the solution to neither the inflation persistence problem nor the output persistence problem.
} 
lem. Several researchers have explained the dependence of inflation rates on their lagged values, based on several factors. One of the most important explanations for reconciling the theoretical and empirical analysis is that agents do not behave rationally and their expectations are adaptive (past values are sufficient statistics of future expected values). For example, Gali and Gertler (1999) assume that at least some firms do not set prices in the way that the Calvo model proposes. These firms do not take into account future discounted expected marginal costs when setting the price they are going to charge consumers. In fact, these myopic firms only look at past prices when setting their new price. The main criticism that can be made of this approach is that it is difficult to sustain irrational behaviour for a long period of time. ${ }^{4}$

Fuhrer and Moore (1995) build a model using staggered Taylor labour contracts. If the wage is set by agents concerned with real wages, then inflation may be persistent. The drawbrack of this approach is that the model is not microfounded and wage setting rules are taken as given.

Ascari and Garcia (2000) propose an alternative approach. They develop a theoretical model whose key ingredient is the fact that agents envy other agents' real wages. Under some assumptions, this model proves that current inflation may indeed depend on past inflation. The main caveat is that it may be more plausible to assume that agents will envy others' consumption, total income or total wealth rather than their real wages.

This paper proposes that the existence of indexation clauses in long-term labour contracts (linking wage movements to past observed inflation rates) could explain the relationship between current inflation and lagged inflation. Of course, I do not believe that this is the only possible explanation - it has some drawbacks - but it does have to be taken into account when trying to explain inflation dynamics.

\footnotetext{
${ }^{4}$ Roberts (1997) finds that expectations are neither fully adaptive nor fully rational nor an average between rational and adaptative expectations.
} 
Holland (1995) remarks that, in the United States, 39\% of the collective agreements concluded in 1990 covering more than 1,000 workers included indexation clauses. Taylor (1998) also points out that $50 \%$ of the multi-year contracts concluded in the unionised sector in the United States included this type of clauses. To be fair, we must recognise that collective agreements only cover a small fraction of the US labour force (around 10\%), although Holland (1988) proposes that these collective agreements may well be used as an example by non-covered workers when the time comes for a re-negotiation of their wages (so -called "implicit indexation"). Thus, he thinks that $39 \%$ may be a reliable figure for the overall degree of indexation in the US economy. If we assume that this is a fair figure, then it is worth taking this fact into consideration.

In the euro area, some countries exhibit a rather high degree of indexation in the labour market. In Belgium, $80 \%$ of the labour force was subject to these clauses in 1998. In Luxembourg, the figure was $90 \%$ in 1999. In other European countries, indexed wages have been very common in the past, although their importance has since decreased substantially (Emerson (1986), Garcia Perea and Gomez (1993)). ${ }^{5}$

Previous research studies on the indexation of wages to lagged inflation have had contradictory results. On the one hand, Sbordone (2001) finds that indexation to lagged inflation does not really help to explain US wage and price movements. On the other hand, Christiano, Eichembaum and Evans (2001) mantain that that staggered fully-indexed wages may be more important than staggered prices when trying to capture US inflation dynamics. Among other things, this paper allows the degree of indexation to vary in an attempt to ascertain whether plausible degrees of indexation can explain US inflation persistence or not.

This paper is structured as follows. Section 2 presents a dynamic general

\footnotetext{
${ }^{5}$ For other countries see, for example, Simonsen (1983) and Fischer (1985).
} 
equilibrium model in which wages are indexed to past inflation. In section 3 the reduced form solutions and the impulse response functions implied by the model are calculated. Section 4 deals with welfare issues: first, the optimal monetary policy reaction function is calculated for a given degree of indexation; then the optimal degree of indexation to lagged inflation is obtained. Section 5 extends the model to a two-country configuration and calculates the effects of a common monetary policy embracing two countries characterised by different degrees of indexation. The conclusions are presented in Section 6 .

\section{The model}

\subsection{Assumptions}

To keep things as simple as possible aiming to get the basic intuitions, let us start with a model without uncertainty. ${ }^{6}$ There are two types of agents: households and firms. On the one hand, there is a continuum of households between 0 and 1 , indexed by $i$. They live for two periods. One half of the population dies every period and is replaced by the same amount of households (overlapping generations). Thus, there is no population growth. The new households are exactly identical to the ones that have just died. The households' intertemporal utility function takes the form,

$$
U\left(V_{i t}, N_{i t}\right)=\sum_{t=0}^{1} \beta^{t}\left[\log \left[\int_{0}^{1} V_{i j t}^{1 / \mu} d j\right]^{\mu}+\lambda_{m} \log \frac{M_{i t}}{P_{t}}-\lambda_{n} N_{i t}\right]
$$

where $V_{i t}$ is a vector that represents the household consumption at time $t$ of each variety $j$ of the consumption good. $\frac{M_{i t}}{P_{t}}$ denotes the real balances held by household $i$ at period $t$. $N_{i t}$ is the number of hours devoted to work and

$$
\mu=\frac{\varepsilon}{\varepsilon-1}>1
$$

where $\varepsilon$ is the constant elasticity of substitution between varieties. $\beta$ is the intertemporal discount factor (that is equal to $\frac{1}{1+\rho}, \rho$ being the intertemporal

\footnotetext{
${ }^{6}$ This assumption will be relaxed below.
} 
discount rate). Household resources are composed by wages and firms' profits. Each household is supposed to have a unique ability to produce one variety of the consumption good but it is not able to produce any other. Moreover, any household can issue private bonds to finance current expenditure. The bonds have to be repaid one period later and the borrower must pay a nominal interest rate of $r_{t}$ to the lender.

On the other hand, there is a continuum of firms between 0 and 1 , indexed by $j$. They are modelled just as a technology. Each firm produces a different variety of the consumption good and sells it in a monopolisticly competitive environment, choosing the price of its variety to maximize profits. This model might be interpreted as a model in which each household founds a firm aiming to sell the variety of the consumption good that the household is able to produce. To diversify idiosyncratic risks, the founder sells its shares to all other households to diversify her portfolio. The production function takes the form,

$$
Y_{j t}=N_{j t} \quad j \in[0,1]
$$

which exhibits constant returns to scale. $Y_{j t}$ represents the level of output of firm $j$ at time $t$. Firms are arbitrarily divided into two sectors: Firms indexed by $j \in[0,0.5]$ belong to sector 1 while firms indexed by $j \in(0.5,1]$ belong to sector 2 .

The monetary authority supplies money to the households and conducts monetary policy using the nominal interest rate as the policy instrument. ${ }^{7}$ This central bank is assumed to minimise the following loss function,

$$
L(\pi, c)=-\frac{1}{2} \sum_{j=0}^{\infty} \beta^{j} E_{t}\left[\eta \pi_{t+j}^{2}+\widehat{c}_{t+j}^{2}\right]
$$

which means that the central bank cares about current and future expected inflation, $\pi$, and current and future expected deviations of output from poten-

\footnotetext{
${ }^{7}$ In the absence of the zero bound on nominal interest rates, it is equivalent to use the money supply as the policy instrument.
} 
tial output (the output gap, $\widehat{c}) . \eta$ is a measure of the relative weight given by the central bank to the inflation rate as opposed to the output gap.

A very important set of assumptions regarding the wage-setting procedure follows. First, let us assume that all labour contracts last for two periods. Second, each sector negotiates its wage at a different point in time (staggered contracts). Finally, the wage per hour during the second period of each contract equals the wage per hour set at the beginning of the contract plus an additional amount related to the inflation rate observed during the first period of the contract (indexation to lagged inflation).

The results that will be obtained here hinge upon these three assumptions. Hence, they must be somehow justified. First, the introduction of long labour contracts instead of one-period contracts may be theoretically justified by the existence of a fixed renegotiation cost (Ball (1987)). The framework with twoperiod contracts (as opposed to even longer contracts) has been chosen because the algebra is less cumbersome.

Second, staggered contracts may turn out to be the optimal outcome from a model in which firms suffer informational problems and are affected by idiosyncratic shocks (Ball and Cecchetti (1988)). The same result is obtained from a model with significant relative (real versus nominal) disturbances (Fethke and Policano (1984)). Furthermore, staggered contracts are usually observed in practice (Taylor (1998)).

Last but not least, the theoretical justification for the introduction of the indexation clauses that link wage changes to lagged inflation (instead of expected future inflation) is difficult to find.$^{8}$ Nevertheless, some empirical justifications could be provided. For example, Fischer (1977) states that "wage

\footnotetext{
${ }^{8}$ Gray (1978), Gray (1983), Fischer (1986), Woglom (1990) Cho, Cooley and Phaneuf (1997) and Laséen (2000) theoretically justify the existence of indexation clauses that link wage movements to the current inflation rate. But Jadresic (1998) asserts that those results are not robust when indexation to lagged inflation is considered. Crowley (1997) finds that backward-looking indexation may be welfare-improving at times of unchanging policies but not during price-stabilization programs.
} 
indexing typically applies to long-term contracts and adjusts the wage for later periods of a contract in accordance with the realized behavior of the price level over the preceding periods". In the same direction, Simonsen (1983) points out that "two types of arrangement have been widely adopted for wages: the Trigger Point System ${ }^{9}$ and lagged inflation". Kaufman and Woglom (1986) remark that, in the US, virtually all of the clauses link absolute increases in pay to absolute increases in the lagged value of the Consumer Price Index. More recently, Jadresic (1998) asserts that indexation to lagged inflation "is the usual type of wage indexation observed in practice". Moreover, from a legal point of view, to index wages to future expected inflation rates could be difficult to implement in practice.

\subsection{The timing of the model}

For simplicity, let us divide each period in two different stages. During the first stage, the wage-setting decision is taken by the households that have just been born (one half of the population). The other half sees their wages automatically changed by the indexation clauses. These clauses are explained in detail below. During the second stage, all agents observe the wages. Then, the price-setting decision is taken by the firms while production, consumption and monetary policy actions take place at the same time.

To solve the theoretical model, a subgame perfect equilibrium is calculated. Thus, let us start from the decisions taken during the second stage and, once the consumption and pricing decision rules have been obtained, the optimal wage-setting decision will be addressed.

As the households and the firms are atomistic, they take the aggregate variables (the aggregate consumption and prices) as given. In other words, they do not take into account the effect of their individual decisions on the

\footnotetext{
${ }^{9}$ The Trigger Point System establishes an interval for the relevant price index. While the index is inside the bands, wages remain stable. However, if the price index touches a band, wages automatically change to keep the workers' purchasing power unchanged.
} 
macroeconomic variables.

\subsection{Consumption decision}

The aim of this subsection is to obtain an expression for the optimal consumption demands. To simplify algebra, let us assume that each household is going to supply all the labour force that is demanded by the firm it is working for. Therefore, the labour supply is not a decision variable ${ }^{10}$. The way of proceeding is as follows: An atomistic household chooses the allocation of a given level of expenditure on the continuum of varieties to maximise utility, given prices and aggregate demand

$$
\begin{aligned}
& \quad \begin{array}{l}
\text { Max } \\
\left\{V_{i j}\right\}
\end{array} \quad \int_{0}^{1} V_{i j}{ }^{\frac{1}{\mu}} d j \\
& \text { s.t. } \quad \int_{0}^{1} P_{j} V_{i j} d j=E_{i}
\end{aligned}
$$

where $V_{i j}$ is the amount of variety $j$ that is consumed by household $i . P_{j}$ is the price of this variety and $E_{i}$ is the total expenditure of the household $i$. It is important to note that to solve a static problem has nothing to do with any assumption on consumption smoothing over time. In fact, smoothing behaviour is going to affect the total expenditure, which is considered as given. The well-known solution is,

$$
V_{i j}=\left(\frac{P_{j}}{P}\right)^{-\varepsilon} C_{i}
$$

where $P$ and $C_{i}$ are defined as follows

$$
\begin{gathered}
P=\left[\int_{0}^{1} P_{j}^{1-\varepsilon} d j\right]^{\frac{1}{1-\varepsilon}} \\
C_{i}=\left[\int_{0}^{1} V_{i j}^{\frac{1}{\mu}} d j\right]^{\mu}
\end{gathered}
$$

$P$ can be interpreted as some aggregate price index. It is a geometric average of the individual prices. $C_{i}$ could be seen as the level of consumption

\footnotetext{
${ }^{10}$ The results are basically the same if endogenous labour supply is taken into account.
} 
of a composite good and $P C_{i}=E_{i}$. The demand of each variety decreases when either the price of the variety increases or the aggregate price index decreases or total household consumption decreases. ${ }^{11}$

These types of demands have been widely used since total household consumption is the only variable needed to know the demands for all varieties, given prices. To calculate the total household consumption demand and the real balances demand, households maximise utility subject to the intertemporal budget constraint, taken the wages and prices as given. For example, a household $i$ that was born at period zero solves

$$
\begin{gathered}
\text { Max } \\
\left.\qquad C_{i t}, \frac{M_{i t}}{P_{t}}\right\} \sum_{t=0}^{1} \beta^{t}\left[\log C_{i t}+\lambda_{m} \log \frac{M_{i t}}{P_{t}}-\lambda_{n} N_{i t}\right] \\
\text { s.t. } \quad P_{0} C_{i 0}+M_{i 0}+\frac{1}{1+r_{0}}\left(P_{1} C_{i 1}+M_{i 1}-M_{i 0}\right)= \\
=W_{i 0} N_{i 0}+\Pi_{0}+\frac{1}{1+r_{0}}\left(W_{i 1} N_{i 1}+\Pi_{1}\right)
\end{gathered}
$$

where $W_{i}$ denotes the nominal wage per hour and $\Pi$ represents the nominal profits distributed by the firms. Let us assume that all households hold the same diversified portfolio. That is the reason why the subscript $i$ is removed from $\Pi$. Zero household initial wealth is assumed. The first order conditions are

$$
\begin{aligned}
\frac{1}{C_{i 0}} & =\kappa P_{0} \\
\frac{\beta}{C_{i 1}} & =\kappa\left(\frac{1}{1+r_{0}}\right) P_{1} \\
\frac{\lambda_{m} P_{0}}{M_{i 0}} & =\kappa P_{0}\left(1-\frac{1}{1+r_{0}}\right) \\
\frac{\lambda_{m} \beta P_{1}}{M_{i 1}} & =\kappa P_{1} \frac{1}{1+r_{0}}
\end{aligned}
$$

Combining the first and the second first order conditions, the Euler Equation may be obtained

\footnotetext{
${ }^{11}$ As in Blanchard and Kiyotaki (1987).
}

$$
1=\beta\left(1+r_{0}\right) \frac{P_{0} C_{i 0}}{P_{1} C_{i 1}}
$$


Combining the first and the third first order conditions, the money demand equations are

$$
\begin{aligned}
\frac{M_{i 0}}{P_{0}} & =\lambda_{m}\left(1-\frac{1}{1+r_{0}}\right)^{-1} C_{i 0} \\
\frac{M_{i 1}}{P_{1}} & =\lambda_{m}\left(\frac{1}{1+r_{0}}\right)^{-1} C_{i 1}
\end{aligned}
$$

and substituting these expressions into the budget constraint,

$$
C_{i t}=\frac{\beta^{t}}{\left(1+\lambda_{m}\right)(1+\beta) P_{t}}\left[\sum_{j=0}^{1}\left(\frac{1}{1+r_{0}}\right)^{j}\left[W_{i j} N_{i j}+\Pi_{j}\right]\right]
$$

Finally, aggregate consumption in this economy is defined as follows,

$$
C_{t}=\int_{0}^{1} C_{i t} d i
$$

\subsection{Monetary authority decision}

To solve the model, a fixed money supply rule is assumed,

$$
M^{s}=\bar{M}
$$

In this case, the nominal interest rate plays the role of clearing the money market. Note that $\bar{M}$ serves as a nominal anchor for the economy. The main reason to assume a fixed money supply is to keep the log-linearizing process a simple as possible. As the log-linearized inflation and output equations are conditional on the behaviour of the nominal interest rates, the monetary authority rule may be changed later without varying these conditional equations. (Moreover, the fixed money supply assumption will be relaxed below, allowing for more conventional nominal interest rate rules.)

\subsection{Price-setting decision}

To calculate firm's optimal pricing policy, let us consider an atomistic firm, labeled $j$, that has to choose the price of the variety it produces, $P_{j}$, which 
maximises its profits subject to the demand it faces and its production function. Wages are taken as given because they were set during the first stage of each period. I assume that each firm has only one worker ${ }^{12}$. Furthermore, and again for the sake of simplicity, output is supposed to be demand-determined,

$$
\begin{array}{lc}
\begin{array}{l}
\text { Max } \\
\left\{P_{j}\right\}
\end{array} & P_{j} V_{j}-W_{j} N_{j} \\
\text { s.t. } & V_{j}=N_{j}=\left(\frac{P_{j}}{P}\right)^{-\varepsilon} C
\end{array}
$$

Substituting the constraints into the maximand, the first order condition is

$$
\left(P_{j}-W_{j}\right)(-\varepsilon) P_{j}^{-\varepsilon-1}+P_{j}^{-\varepsilon}=0
$$

Solving for $P_{j}$ it can be found that the optimal price is a mark-up over the marginal cost,

$$
P_{j}=\frac{\varepsilon}{\varepsilon-1} W_{j}=\mu W_{j}
$$

This expression shows that the price a firm is going to charge consumers is going to depend on two terms. The first one, $\mu$, represents the firm's monopolistic power. It is higher than 1 (the value associated with perfect competition as $\varepsilon \rightarrow \infty)$. The higher the $\mu$, the higher the degree of market power and the higher the price the firm is able to set (with the monopoly price as a ceiling). The second term represents the marginal cost of firm $j$. The higher the costs the firm must face, the higher the price of the variety.

\subsection{Wage decision}

Once the optimal behaviour of firms and households has been analysed, the next objective is to obtain optimal wage-setting. The households take wage decisions when they are born and they enjoy all the bargaining power because

\footnotetext{
${ }^{12}$ The same results would be obtained if several identical workers are assigned to each firm.
} 
each worker is able to produce only one variety of the consumption good. In this context, the current worker may not be substituted by any other. ${ }^{13}$

Each household knows that the wage it is going to receive during the second period of its contract depends heavily on the wage set during the first period, because of the existence of indexation clauses. Household $i$ solves the following optimisation program. It maximises its utility given the optimal decision rules and the indexation system,

$$
\begin{gathered}
\begin{array}{c}
\text { Max } \\
\left\{W_{i 0}\right\}
\end{array} \sum_{t=0}^{1} \beta^{k}\left[\log C_{i t}+\lambda_{m} \log \frac{M_{i t}}{P_{t}}-\lambda_{n} N_{i t}\right] \\
\text { s.t. } C_{i t}=\frac{\beta^{t}}{\left(1+\lambda_{m}\right)(1+\beta) P_{t}}\left[\sum_{j=0}^{1}\left(\frac{1}{1+r}\right)^{j}\left[W_{i j} N_{i j}+\Pi_{j}\right]\right] \\
\frac{M_{i 0}}{P_{0}}=\lambda_{m}\left(1-\frac{1}{1+r}\right)^{-1} C_{i 0} \\
\frac{M_{i 1}}{P_{1}}=\lambda_{m}\left(\frac{1}{1+r}\right)^{-1} C_{i 1} \\
N_{i t}=\left[\frac{\mu W_{i t}}{P_{t}}\right]^{-\varepsilon} C_{t} \\
\Pi_{t}=\frac{1}{\varepsilon} P_{t} C_{t} \\
W_{i 1}=W_{i 0}\left(1+\delta \pi_{0}\right)
\end{gathered}
$$

where $\pi_{t}$ is the inflation rate during period $t$, that is $\frac{P_{t}-P_{t-1}}{P_{t-1}}$. Substituting the constraints into the maximand, the first order condition could be obtained,

\footnotetext{
${ }^{13}$ Furthermore, this is the way to avoid the need for a commitment technology. This technology is necessary for shareholders to reach an agreement about the wages they would set. However, there is a continuum of shareholders and to assume they may put themselves in agreement is, at least, difficult to support. Besides, this group of shareholders would constitute a council where all prices and wages could be set. Even in this case, the results obtained here would not differ qualitatively.
} 


$$
\begin{aligned}
& -\left[\begin{array}{c}
\left(\frac{W_{i 0}}{P_{0}}\left[\frac{\mu W_{i 0}}{P_{0}}\right]^{-\varepsilon}+\frac{1}{\varepsilon}\right) C_{0}+ \\
\frac{1}{1+r_{0}}\left(\frac{W_{i 0}\left(1+\delta \pi_{0}\right)}{P_{0}}\left[\frac{\mu W_{i 0}\left(1+\delta \pi_{0}\right)}{P_{1}}\right]^{-\varepsilon}+\frac{1}{\varepsilon}\right) C_{1}
\end{array}\right]^{-1} \\
& (\varepsilon-1)(1+\beta)\left(1+\lambda_{m}\right)\left(\left(\frac{W_{i 0}}{P_{0}}\right)^{1-\varepsilon}+\beta\left(1+\delta \pi_{0}\right)^{1-\varepsilon} \frac{W_{i 0}}{P_{0}}\left(\frac{W_{i 0}}{P_{1}}\right)^{\varepsilon}\right) \\
& +\varepsilon \lambda_{n}\left[C_{t}\left(\frac{W_{i t}}{P_{t}}\right)^{-\varepsilon}+\beta C_{t+1}\left(\frac{W_{i t}\left(1+\delta \pi_{t}\right)}{P_{t+1}}\right)^{-\varepsilon}\right]=0
\end{aligned}
$$

The key variables for the household are the real wages at $t$ and $t+1$. The higher the expected price during these periods, the higher the wage the household is going to set. The effect of aggregate consumption on the wage is clear: the higher the aggregate consumption is, the higher are the demands for each variety and the higher the disutility associated to the job. Then, the household raises the wage in order to raise the price of the variety produced by the firm and therefore reduce its demand.

To analyse in a deeper way the effects of these variables and the parameters on the wage, the next step is to log-linearize the first order condition. The loglinearized functional form is calculated around the zero-inflation equilibrium because this equilibrium has the feature of constancy of wages and prices. The equations that define the equilibrium are

$$
\begin{aligned}
M_{t}^{d} & =M_{t}^{s}=M^{*}=\bar{M} \\
W_{i t} & =W_{t}=W^{*}=\frac{2 \mu \lambda_{n} \beta(1-\beta)}{\lambda_{m}\left(1+\lambda_{m}\right)} M^{*} \\
P_{j t} & =P_{t}=P^{*}=\mu W^{*} \\
C_{t} & =C^{*}=\frac{1+\lambda_{m}}{\mu^{2} \lambda_{n}} \\
r_{t} & =r=\frac{1}{\beta}-1
\end{aligned}
$$

As the labour, goods and money markets are in equilibrium, the Walras law assures that the bond market is in equilibrium as well. The derivation 
of the log-linearized functional form can be found in Appendix A. The final expression is,

$$
\begin{aligned}
\widehat{w}_{s 0}= & \frac{\varepsilon^{2} \lambda_{n} \mu+(1-\varepsilon)}{\left(\varepsilon^{2} \lambda_{n}(\mu+\beta)+(1+\beta)(1-\varepsilon)\right)} \widehat{p}_{0}+\frac{\beta\left(\varepsilon^{2} \lambda_{n}+(1-\varepsilon)\right)}{\left(\varepsilon^{2} \lambda_{n}(\mu+\beta)+(1+\beta)(1-\varepsilon)\right)} \widehat{p}_{1} \\
& -\frac{\beta \delta\left(\varepsilon^{2} \lambda_{n}+(1-\varepsilon)\right)}{\left(\varepsilon^{2} \lambda_{n}(\mu+\beta)+(1+\beta)(1-\varepsilon)\right)} \pi_{0} \\
& +\frac{\varepsilon \lambda_{n}}{\left(\varepsilon^{2} \lambda_{n}(\mu+\beta)+(1+\beta)(1-\varepsilon)\right)}\left(\widehat{c}_{0}+\beta \widehat{c}_{1}\right)
\end{aligned}
$$

where a variable under a hat denotes a log-deviation of the variable with respect to the equilibrium value. The subscript $i$ has been replaced by the subscript $s$. This subscript identifies the sector that is negotiating at time $t$. The reason for this substitution relies on that all the households negotiating at time 0 are going to choose the same wage $\widehat{w}_{s 0}$. The intuitions that have been obtained from the first order condition are clear now: the wage set is going to be a weighted average of current and future prices (and this fact is independent of the degree of indexation). Current inflation is obviously important if contracts are indexed to lagged inflation $(\delta \neq 0)$. Finally, the effect of both current and future output gaps is decreasing as $\varepsilon$ increases because the higher the $\varepsilon$ the lower the response of the consumers to an increase in prices. Using the following approximation

$$
\pi_{0} \simeq \widehat{p}_{0}-\widehat{p}_{-1}
$$

this expression could be obtained

$$
\widehat{w}_{s 0}=\varpi_{1} \widehat{p}_{-1}+\varpi_{2} \widehat{p}_{0}+\varpi_{3} \widehat{p}_{1}+\varpi_{4} \widehat{c}_{0}+\varpi_{5} \widehat{c}_{1}
$$

where

$$
\begin{aligned}
\varpi_{1} & =\frac{\beta \delta\left(\varepsilon^{2} \lambda_{n}+(1-\varepsilon)\right)}{\varepsilon^{2} \lambda_{n}(\mu+\beta)+(1+\beta)(1-\varepsilon)} \\
\varpi_{2} & =\frac{\varepsilon^{2} \lambda_{n} \mu+(1-\beta \delta)(1-\varepsilon)-\beta \delta \varepsilon^{2} \lambda_{n}}{\varepsilon^{2} \lambda_{n}(\mu+\beta)+(1+\beta)(1-\varepsilon)} \\
\varpi_{3} & =1-\varpi_{1}-\varpi_{2} \\
\varpi_{4} & =\frac{\varepsilon \lambda_{n}}{\left(\varepsilon^{2} \lambda_{n}(\mu+\beta)+(1+\beta)(1-\varepsilon)\right)} \\
\varpi_{5} & =\beta \varpi_{4}
\end{aligned}
$$


It can be seen that wages are a weighted average of current, future and (if indexation to lagged inflation is present) past prices. I am going to label this equation as the "wage-setting equation". From this point, it is possible to solve for the inflation rate. The derivation of the inflation equation can be found in Appendix B. The final outcome is,

$$
\pi_{0}=\rho_{1} \pi_{-1}+\rho_{2} \pi_{1}+\rho_{3} \widehat{c}_{-1}+\rho_{4} \widehat{c}_{0}+\rho_{5} \widehat{c}_{1}
$$

where

$$
\begin{aligned}
& \rho_{1}=\rho_{0}^{-1}\left[\frac{1}{2}\left(1+\frac{2 \varpi_{3}}{2 \varpi_{2}+\varpi_{3} \delta}\right) \varpi_{1}+\frac{\delta}{2}\right] \\
& \rho_{2}=\rho_{0}^{-1}\left[\frac{1}{2}\left(1+\frac{2 \varpi_{3}}{2 \varpi_{2}+\varpi_{3} \delta}\right) \varpi_{3}\right] \\
& \rho_{3}=\rho_{0}^{-1}\left[1+\frac{2 \varpi_{3}}{2 \varpi_{2}+\varpi_{3} \delta} \varpi_{4}-\frac{\left(2 \varpi_{1}-\delta \varpi_{3}\right) \varpi_{4}}{2 \varpi_{2}+\varpi_{3} \delta}+\frac{\varpi_{4}}{2}\right] \\
& \rho_{4}=\rho_{0}^{-1}\left[\frac{1}{2}\left(1+\frac{2 \varpi_{3}}{2 \varpi_{2}+\varpi_{3} \delta}\right)\left(\varpi_{4}-\varpi_{5}\right)-\frac{\left(2 \varpi_{1}-\delta \varpi_{3}\right) \varpi_{5}}{2 \varpi_{2}+\varpi_{3} \delta}+\frac{\varpi_{5}}{2}\right] \\
& \rho_{5}=\rho_{0}^{-1}\left[\frac{1}{2}\left(1+\frac{2 \varpi_{3}}{2 \varpi_{2}+\varpi_{3} \delta}\right) \varpi_{5}\right]
\end{aligned}
$$

and

$$
\rho_{0}=1-\frac{1}{2}\left(1+\frac{2 \varpi_{3}}{2 \varpi_{2}+\varpi_{3} \delta}\right) \varpi_{2}+\frac{\left(2 \varpi_{1}-\delta \varpi_{3}\right) \varpi_{3}}{2 \varpi_{2}+\varpi_{3} \delta} \varpi_{1}
$$

The current inflation rate depends on the future expected inflation rate and, to the extent that the degree of indexation is different from zero, on the past inflation rate. As the future inflation is expected to increase, current inflation is going to raise as the New Phillips Curve proposes. Finally, the current inflation rate depends on the past, current and future output gaps.

If a shock $s_{t}$ hits the economy after the wages have been set ${ }^{14}$, under the

\footnotetext{
${ }^{14}$ The easiest cases are either to think about $s_{t}$ as a permanent technology shock, that is,
}

$$
\begin{aligned}
Y_{t} & =A_{t} N_{t} \\
A_{t} & =A_{t-1} \exp \left(-s_{t}\right)
\end{aligned}
$$

or to consider $s_{t}$ as a cost-push shock. 
rational expectations assumption, the wage-setting equation is,

$$
\widehat{w}_{s 0}=\varpi_{1} \widehat{p}_{-1}+\varpi_{2} E_{-1} \widehat{p}_{0}+\varpi_{3} E_{-1} \widehat{p}_{1}+\varpi_{4} E_{-1} \widehat{c}_{0}+\varpi_{5} E_{-1} \widehat{c}_{1}
$$

and expected inflation is driven by

$$
E_{-1} \pi_{0}=\rho_{1} \pi_{-1}+\rho_{2} E_{-1} \pi_{1}+\rho_{3} \widehat{c}_{-1}+\rho_{4} E_{-1} \widehat{c}_{0}+\rho_{5} E_{-1} \widehat{c}_{1}+\phi s_{-1}
$$

where the last term represents a set of forecast errors and forecast revisions that took place once that $s_{t-1}$ is known $^{15}$. The sign of the coefficient $\phi$ is undetermined but it is positive when plausible values are assigned to the parameters of the model. Thus, the Phillips curve implied by this model takes the form

$$
\pi_{0}=\rho_{1} \pi_{-1}+\rho_{2} E_{-1} \pi_{1}+\rho_{3} \widehat{c}_{-1}+\rho_{4} E_{-1} \widehat{c}_{0}+\rho_{5} E_{-1} \widehat{c}_{1}+\phi s_{-1}+s_{0}
$$

\subsection{Comparative Statics}

This subsection checks whether the coefficients of both the wage setting equation and the inflation equation vary in a substantial amount when the original parameters change. In particular I am going to focus on $\delta$, the degree of indexation of the economy.

Figure 1 shows the values of the wage-setting equation coefficients for different values of $\delta$, keeping $\varepsilon, \beta, \lambda_{m}$ and $\lambda_{n}$ unchanged $^{16}$. It can be noted that

${ }^{15}$ In particular, $\phi$ is equal to the linear projection of

$$
\begin{aligned}
& {\left[\frac{1}{2}\left(1-\frac{1-\frac{\varpi_{3}}{2}}{\frac{\varpi_{2}}{2}+\delta \frac{\varpi_{3}}{4}}\right) \varpi_{2}+\frac{1}{4} \varpi_{3} \frac{\varpi_{1}}{\frac{\varpi_{2}}{2}+\delta \frac{\varpi_{3}}{4}}\right]\left(E_{-2} \widehat{p}_{-1}-\widehat{p}_{-1}\right)+} \\
& +\left[\frac{1}{2}\left(1-\frac{1-\frac{\varpi_{3}}{2}}{\frac{\varpi_{2}}{2}+\delta \frac{\varpi_{3}}{4}}\right) \varpi_{3}+\frac{1}{4} \varpi_{3} \frac{\varpi_{2}}{\frac{\varpi_{2}}{2}+\delta \frac{\varpi_{3}}{4}}\right]\left(E_{-2} \widehat{p}_{0}-E_{-1} \widehat{p}_{0}\right)+ \\
& +\left[\frac{1}{2}+\frac{\varpi_{3}}{\varpi_{2}+\delta \frac{\varpi_{3}}{2}}\right]\left[\varpi_{4}\left(E_{-2} \widehat{c}_{-1}-\widehat{c}_{-1}\right)+\varpi_{5}\left(E_{-2} \widehat{c}_{0}-E_{-1} \widehat{c}_{0}\right)\right]
\end{aligned}
$$

\footnotetext{
on $s_{t-1}$.

${ }^{16}$ I set $\varepsilon=10$ as Chari, Kehoe and McGrattan (2000). It implies a mark-up of 11 per cent. $\beta=0.96$, the usual value of the discount factor if annual periods of time are considered. $\lambda_{m}=0.2$, consistent with the value estimated by Dib (2001), which turns out to be equal to 0.2359 . $\lambda_{n}=1$ is the value proposed by Gali, Lopez-Salido and Valles (2002), although they use a different functional form.
} 
the coefficient of $\widehat{p}_{t-1}$ is zero if $\delta$ is equal to zero and increases as $\delta$ increases. If the wages are indexed to the past inflation rate, the higher the price at $t-1$ (in terms of deviations with respect to the zero inflation equilibrium), the lower $\pi_{t}$ will be if the system reverts to the equilibrium. The lower $\pi_{t}$, the lower the future wage during the second period of the contract. Forecasting that a lower wage would imply more hours of work, the households that negotiate at $t$ raise the wage they set above equilibrium. The opposite case happens with the coefficient of $\widehat{p}_{t}$, that takes a value over 0.5 if there is no indexation clauses in the economy, but decreases when $\delta$ increases. In any case, the coefficients of $\widehat{p}_{t+1}, \widehat{c}_{t}$ and $\widehat{c}_{t+1}$ are not affected by changes in $\delta$.

Regarding the inflation equation coefficients, an increase in the degree of indexation increases the coefficient of past inflation (Figure 2) because a higher past inflation rate is translated to higher current inflation through the indexation clauses. At the same time, the coefficient of future inflation decreases, capturing the lower degree of forward-looking behaviour when the indexation clauses are present. On the other hand, the three coefficients of aggregate consumption variables diminish when the degree of indexation increases. This is the consequence of the increase in the price inertia generated by the indexation clauses. When $\delta$ is relatively low, prices respond to real economic conditions very quickly. But if $\delta$ is rather large, prices are mainly driven by past prices and, as a secondary source, by real economic conditions.

As a summary, the model predicts that higher degrees of indexation imply higher degrees of inflation persistence (because past prices become more important in the wage-setting equation). At the same time, the degree of nominal rigidity of the economy increases, lowering the speed of the transmision mechanism from the real disequilibria to the prices. 


\section{Model simulations}

In this section, the reduced-form solutions associated to the structural equations are presented. To start with, the equation that drives the output dynamics is needed and may be obtained by log-linearizing the Euler equation of the consumers. This equation does not hold for all the consumers because half of them are going to die next period, but the model can be extended (by introducing either a role for bequests or infinitely lived agents) to get an equation that holds for everyone (in the case of infinitely lived agents, the Phillips curve includes additional terms: future expected inflation rates and output gaps from $t$ to infinity, but all the results remain qualitatively the same and algebra is much more complex). The resulting equation can be called the IS curve.

$$
\widehat{c}_{t}=E_{t} \widehat{c}_{t+1}-\sigma\left(r-E_{t} \pi_{t+1}\right)
$$

The current output gap depends on the expected future stream of the real interest rates. $\sigma$ is the inverse of the constant relative risk aversion coefficient $(\mathrm{CRRA})^{17}$. If the nominal interest rates are higher than inflation expectations, then the output gap is going to decrease (and so does the inflation rate through the Phillips curve).

Why is inflation persistent? Christiano, Eichenbaum and Evans (2001) find an equation that can explain why a unit root is frequently obtained when analysing inflation dynamics. The same procedure can be applied here. From the Phillips curve

$$
\pi_{t}=\rho_{1} \pi_{t-1}+\rho_{2} E_{t-1} \pi_{t+1}+\rho_{3} \widehat{c}_{t-1}+\rho_{4} E_{t-1} \widehat{c}_{t}+\rho_{5} E_{t-1} \widehat{c}_{t+1}+\phi s_{t-1}+s_{t}
$$

\footnotetext{
${ }^{17}$ The derivation of the wage-setting equation and the Phillips curve when the utility function is

$$
U\left(C_{i t}, \frac{M_{i t}}{P_{t}}, N_{i t}\right)=\frac{C_{i t}^{1-\frac{1}{\sigma}}}{1-\frac{1}{\sigma}}+\lambda_{m} \frac{\left[\frac{M_{i t}}{P_{t}}\right]^{1-\frac{1}{\sigma}}}{1-\frac{1}{\sigma}}-\frac{\lambda_{n}}{1+\nu} N_{i t}^{1+\nu}
$$
}

is not included here because it is similar to the one presented above. 
and imposing the steady state stability condition

$$
E_{t-1} \beta^{j}\left(\pi_{t+j}-\pi_{t+j-1}\right) \rightarrow 0
$$

it can be obtained

$$
\begin{aligned}
\pi_{t}= & \frac{\rho_{1}}{1-\rho_{2}} \pi_{t-1}+\frac{1}{1-\rho_{2}} E_{t-1} \sum_{j=0}^{\infty}\left(\rho_{2}\right)^{j}\left[\rho_{3} \widehat{c}_{t-1+j}+\rho_{4} \widehat{c}_{t+j}+\rho_{5} \widehat{c}_{t+1+j}\right]+ \\
& +\frac{1}{1-\rho_{2}}\left[\phi s_{t-1}+s_{t}\right]
\end{aligned}
$$

In Christiano, Eichenbaum and Evans (2001), the degree of indexation is 1. In general, as it was stated in the subsection 2.7, $\rho_{1}$ and $1-\rho_{2}$ are very similar. Therefore, the coefficient of the lagged inflation is close to one. But this does not mean that inflation is persistent at all. If $\rho_{2}$ is near one, the denominator of the output gap and the error terms is close to zero. Hence, a small change in the future expected output gaps or a small perturbation to the economy may lead to a huge jump of inflation rates.

Some simulations of the economy composed by the Phillips curve and the IS curve are going to be run here aiming to see whether plausible (small) degrees of indexation can reproduce the observed inflation autocorrelations in the US.

To calculate the reduced-form solutions associated to the two structural equations of the model, the Minimal State Variable (MSV) approach $^{18}$ is applied here. The complete derivation of the reduced-form solution can be found in Appendix C. For simplicity, $\phi=0$ is assumed, taking into account that this is an assumption that probably will bias the results against persistence ${ }^{19}$ - However, a moving average error term is only able to generate persistence during one period (it is a dynamic process with just one period of memory). Thus, it seems not to be the solution to explain why the inflation rate is persistent in reality.

\footnotetext{
${ }^{18}$ Christiano (2001).

${ }^{19}$ This makes the inflation rate the only state variable of the model.
} 
Finally, from now and after, let us assume that the monetary authority follows an interest rate rule where the nominal interest rate overreacts to changes in the inflation expectations. In particular, let us consider the following rule ${ }^{20}$ $: r_{t}=1.5 E_{t}\left[\pi_{t+1}\right]$. The magnitude of the coefficient (1.5) is irrelevant. To be larger than one is the only thing that is needed. In this case, there is one MSV solution because the steady state is determined by the policy rule.

\subsection{Impulse-response functions}

To calculate the empirical impulse-response function to a shock to the inflation rate, I estimate a bivariate $\operatorname{VAR}(2)$ with US annual data from 1960 to 2000. The two variables that are included in the VAR are the inflation rate, which is ordered first, and the output gap (calculated as the log-difference of the real output with respect to the output trend calculated by the Hodrick-Prescott filter). The estimation results are presented in Table 1 and the implied impulseresponse functions are depicted in Figure 3. The top right pannel accounts for the well-known inflation persistence phenomenon: a transitory shock leads to substantial delayed effects on the inflation rate.

How does the inflation rate implied by the model respond to a shock $s_{t}$ ? Obviously, it depends on the degree of indexation. If the degree of indexation is zero (no indexation case) then the unique stable MSV solution implies no persistence at all in the model, as presented in Figure 4 (top panel). The inflation rate jumps but it returns to its previous level just one period later. The output gaps are zero because the ex-ante real interest rates do not change. It can be observed that the impulse-response function implied by the model does not go out of the standard error bands. This is the result implied by the staggered wage setting model (Taylor (1979)).

Figure 4 (left bottom panel) shows the response of the inflation rate to a

\footnotetext{
${ }^{20}$ This specification is equivalent to a Taylor rule because there is a mapping function from the output gaps to the inflation rates. As the inflation rate is the only state variable of the system, it is a sufficient statistic for the monetary authority.
} 
macroeconomic shock for a small degree of indexation $(\delta=0.15)$. It is not inside the confidence interval either. In other words, when monetary policy is active a small degree of indexation is not enough to explain observed inflation persistence. If the degree of indexation takes an implausible high value $(\delta=$ 1, as in Christiano, Eichembaum and Evans (2001)), the impulse response function is as depicted in Figure 4 (right bottom panel). A very high degree of indexation may explain the observed inflation persistence. But such a high degree of indexation is rarely found in practice.

\subsection{Inflation autocorrelation}

At this point, the following question may arise: What is the percentage of the annual US inflation autocorrelation that can be explained by a relatively low degree of indexation? US annual data from 1961 to 2000 may be used to calculate the empirical inflation autocorrelation coefficient ${ }^{21}$. Its value is to $0.739^{22}$. The inflation autocorrelation implied by the model can be calculated by starting from the reduced form solution

$$
\left[\begin{array}{l}
\pi_{t} \\
\widehat{c}_{t}
\end{array}\right]=A\left[\begin{array}{c}
\pi_{t-1} \\
\widehat{c}_{t-1}
\end{array}\right]+B s_{t}
$$

The variance-covariance matrix of the vector $\left[\pi_{t} \widehat{c}_{t}\right]^{\prime}$ is

$$
V=\operatorname{vec}\left[\operatorname{Var}\left[\begin{array}{c}
\pi_{t} \\
\widehat{c}_{t}
\end{array}\right]\right]=(I-A \otimes A)^{-1}(B \otimes B) \operatorname{vec}\left[\operatorname{Var}\left(s_{t}\right)\right]
$$

where $\otimes$ denotes the Kronecker product. The covariance between $\left[\pi_{t} \widehat{c}_{t}\right]^{\prime}$ and $\left[\pi_{t-1} \widehat{c}_{t-1}\right]^{\prime}$ is

$$
C V=\operatorname{Cov}\left[\begin{array}{ll}
\pi_{t} & \pi_{t-1} \\
\widehat{c}_{t} & \widehat{c}_{t-1}
\end{array}\right]=E\left[\left[\begin{array}{l}
\pi_{t} \\
\widehat{c}_{t}
\end{array}\right]\left[\begin{array}{l}
\pi_{t-1} \\
\widehat{c}_{t-1}
\end{array}\right]^{\prime}\right]=A V
$$

\footnotetext{
${ }^{21}$ defined as $\frac{\operatorname{cov}\left(\pi_{t}, \pi_{t-1}\right)}{\left[\operatorname{var}\left(\pi_{t}\right) \operatorname{var}\left(\pi_{t-1}\right)\right]^{0.5}}$.
}

${ }^{22}$ It is fair to recognise that this coefficient has decreased during the second half of the century: from 1961 to 1970 it was 0.853 . From 1971 to 1980 it drops to 0.533. From 1981 to 1990 it raised 0.636 and for the period 1991-2000 was only about 0.261 . 
The inflation autocorrelation coefficient may be obtained by dividing the upper left element of the $2 \times 2 C V$ matrix over the upper left element of the $2 \mathrm{x} 2 V$ matrix. Figure 5 displays the inflation autocorrelation implied by the model for different small and plausible degrees of indexation. The proportion of the observed inflation autocorrelation that the model is able to explain is, for $\delta=0.15$, slightly over one fifth $^{23}$. Therefore, when trying to explain the inflation persistence phenomenon, wage indexation to lagged inflation may be one part of the story, but it ought not to be the most important one.

\section{Welfare analysis}

In this section, let us consider a role for monetary policy. Monetary authority is assumed to be able to use the nominal interest rate as the monetary policy instrument to minimise a loss function. Therefore, the optimal monetary policy rules may be calculated, for a given degree of indexation. Moreover, given the optimal responses of the monetary authority, the optimal degree of indexation implied by the model may be obtained.

\subsection{Optimal monetary policy}

As stated above, let us assume that the monetary authority may control the nominal interest rate to reduce the central bank's losses coming from the persistent effects of the transitory shocks that affect to the inflation rate. In the model, monetary policy actions take place after the current shock has been observed (the inflation rate is then observed as well) but before both the consumption and employment decisions take place. Thus, the complete model can

\footnotetext{
${ }^{23}$ This fraction increases to almost two thirds during the period 1991-2000.
} 
be summarised by the following equations,

$$
\begin{aligned}
\pi_{t} & =\rho_{1} \pi_{t-1}+\rho_{2} E_{t-1} \pi_{t+1}+\rho_{3} \widehat{c}_{t-1}+\rho_{4} E_{t-1} \widehat{c}_{t}+\rho_{5} E_{t-1} \widehat{c}_{t+1}+s_{t} \\
r_{t} & =f_{t}\left(\widehat{c}_{t-1}, \pi_{t-1}, \pi_{t}\right) \\
\widehat{c}_{t} & =E_{t} \widehat{c}_{t+1}-\sigma\left(r_{t}-E_{t} \pi_{t+1}\right)
\end{aligned}
$$

The aim is to derive the function $f_{t}$ that does the mapping from the observed variables to the nominal interest rate. Let us focus here on the timeinvariant policy rules, that is $f=f_{t}$ for $t \geq 0$.

After the shock is observed by everyone, all the available pieces of information may be summarised by the current inflation rate (the only state variable of the system). In other words, $\pi_{t}$ is a sufficient statistic to decide the current nominal interest rate movements. Against this background, let us consider policy rules of the form,

$$
r_{t}=\tau \pi_{t}
$$

To minimise losses, the monetary authority chooses $\tau^{*}$ to solve the following program,

$$
\begin{aligned}
& \operatorname{Max}-\frac{1}{2} \sum_{j=0}^{\infty} \beta_{C B}^{j} E_{t}\left[\eta \pi_{t+j}^{2}+\widehat{c}_{t+j}^{2}\right] \\
\text { s.t. } \quad & \{\tau\} \quad \pi_{t}=\rho_{1} \pi_{t-1}+\rho_{2} E_{t-1} \pi_{t+1}+\rho_{3} \widehat{c}_{t-1}+\rho_{4} E_{t-1} \widehat{c}_{t}+\rho_{5} E_{t-1} \widehat{c}_{t+1}+s_{t} \\
\widehat{c}_{t}= & E_{t} \widehat{c}_{t+1}-\sigma\left(r_{t}-E_{t} \pi_{t+1}\right) \\
r_{t}= & \tau \pi_{t}
\end{aligned}
$$

The loss function may be interpreted as a second order Taylor approximation to the representative agent's utility function. Thus, a central bank may control the nominal interest rate to reduce the inflation deviations from the zero inflation rate and to smooth the cyclical component of the real output time series. $\eta$ is a measure of the relative weight assigned by the monetary authority to the inflation deviations with respect to the output gaps. If $\eta=0$, the monetary authority only cares about the output gaps. If $\eta=1$ both goals 
are weighted the same. If $\eta=\infty$, the central bank only cares about the inflation developments. $\beta$ represents the intertemporal discount factor of the central bank.

From the reduced-form equations implied by the model, it is known that

$$
\begin{aligned}
E_{t} \pi_{t+1} & =A_{1}(1,1) \pi_{t}+A_{1}(1,2) \widehat{c}_{t} \\
E_{t} c_{t+1} & =A_{1}(2,1) \pi_{t}+A_{1}(2,2) \widehat{c}_{t}
\end{aligned}
$$

The $A_{1}$ matrix is not going to be the equal to the feedback component calculated before because the behaviour of the nominal interest rate may be different (unless $r_{t}=1.5 E_{t} \pi_{t+1}$ turns out to be the optimal policy rule). Combining these two equations with the IS equation yields,

$$
\widehat{c}_{t}=\frac{A_{1}(2,1)+\sigma A_{1}(1,1)}{1-A_{1}(2,2)-\sigma A_{1}(1,2)} \pi_{t}-\frac{\sigma}{1-A_{1}(2,2)-\sigma A_{1}(1,2)} r_{t}
$$

and plugging the monetary policy rule in,

$$
\widehat{c}_{t}=\frac{A_{1}(2,1)+\sigma\left(A_{1}(1,1)-\tau\right)}{1-A_{1}(2,2)-\sigma A_{1}(1,2)} \pi_{t}
$$

Therefore, inflation expectations are given by

$$
E_{t} \pi_{t+1}=\left[A_{1}(1,1)+\frac{A_{1}(1,2)\left[A_{1}(2,1)+\sigma\left(A_{1}(1,1)-\tau\right)\right]}{1-A_{1}(2,2)-\sigma A_{1}(1,2)}\right] \pi_{t}
$$

Substituting (13) and (14) into the loss function, the monetary authority problem takes the form,

$$
\begin{gathered}
\operatorname{Max}_{\{\tau\}} \quad-\frac{1}{2} \sum_{j=0}^{\infty} \beta_{C B}^{j}\left(\eta+\left(\frac{A_{1}(2,1)+\sigma\left(A_{1}(1,1)-\tau\right)}{1-A_{1}(2,2)-\sigma A_{1}(1,2)}\right)^{2}\right) \\
{\left[A_{1}(1,1)+\frac{A_{1}(1,2)\left[A_{1}(2,1)+\sigma\left(A_{1}(1,1)-\tau\right)\right]}{1-A_{1}(2,2)-\sigma A_{1}(1,2)}\right]^{2 j} \pi_{t}^{2}}
\end{gathered}
$$

As $\pi_{t}$ is determined before the monetary policy decision is taken, the central bank chooses $\tau$ to,

$$
\begin{gathered}
\operatorname{Max}_{\{\tau\}}-\frac{1}{2}\left(\eta+\left(\frac{A_{1}(2,1)+\sigma\left(A_{1}(1,1)-\tau\right)}{1-A_{1}(2,2)-\sigma A_{1}(1,2)}\right)^{2}\right) \\
\left(1-\beta\left[A_{1}(1,1)+\frac{A_{1}(1,2)\left[A_{1}(2,1)+\sigma\left(A_{1}(1,1)-\tau\right)\right]}{1-A_{1}(2,2)-\sigma A_{1}(1,2)}\right]^{2}\right)^{-1}
\end{gathered}
$$


The elements of the matrix $A_{1}$ depend on $\tau$. To deal with this issue, let us consider a grid of values for $\tau \in[0.0001,0.0002,0.0003, \ldots, 0.4]$. For each pair $(\delta, \tau)$, the matrix $A_{1}$ and the expected losses may be calculated. Finally, $\tau^{*}$ is the value of the parameter that minimises the expected losses for a given $\delta$. The optimal values of $\tau$ for some low values of $\delta$ are displayed in Figure 6 $(\text { top panel })^{24}$. As the inflation autocorrelation increases, $\tau^{*}$ increases. To get some intuition from this result, the implied Taylor-based policy rule is

$$
r_{t}=\tau^{\prime} E_{t} \pi_{t+1}
$$

Figure 6 (bottom panel) shows the optimal value $\tau^{\prime}$ calculated as

$$
\tau^{\prime}=\left[A_{1}(1,1)+\frac{A_{1}(1,2)\left[A_{1}(2,1)+\sigma\left(A_{1}(1,1)-\tau^{*}\right)\right]}{1-A_{1}(2,2)-\sigma A_{1}(1,2)}\right] \tau^{*}
$$

The Taylor-based rule parameter is larger than one, implying that the monetary authority increases the real interest rate when the inflation expectations move up. The larger the degree of indexation, the larger the reaction of the nominal interest rate to the inflation expectations when following the optimal policy: if the inflation autocorrelation is low, a shock has small effects on the future macroeconomic conditions and large adjustments of the nominal interest rate are not needed. However, if the inflation rate is following a persistent process, a shock may lead to long-lasting effects. Thus, the optimal monetary authority reactions have to be stronger to prevent large expected future losses. In other words, to keep inflation on target is more costly (in terms of consumption) when the inflation autocorrelation is higher than when it is lower.

\footnotetext{
${ }^{24}$ In the case of no indexation, the optimal monetary policy implied by the model is to set $\tau^{*}=0$, because current inflation is unavoidable and future expected inflation is always zero (there is no persistence anymore). Current movements of nominal interest rates only lead to output deviations from the potential output.
} 


\subsection{Optimal degree of indexation}

Once that optimal responses have been calculated for each degree of indexation, what is the degree of indexation that minimises the expected losses? Figure 7 plots the relative expected losses, in output gap standard deviations, for each degree of indexation.

Three conclusions may be obtained. First, the optimal degree of indexation is no indexation at all. Nevertheless, this result is model-specific since the theoretical model examines only the costs of the indexation scheme but not the potential benefits. Second, the magnitude of the expected losses is rather large if $\delta>0$. And last but not least, the expected losses increase more than proportionally when the degree of indexation increases. Importantly, this result only depends upon the assumption of the loss function being quadratic in inflation and output gap deviations. Following the aforementioned elements, the persistence of the inflation rate stemming from a positive degree of indexation fosters persistent inflation deviations from the policy target. As the central bank is concerned about the output gap, the larger the degree of indexation, the larger the persistent inflation deviations from the policy target. Finally, the quadratic term leads to a more-than-proportional increase of the expected losses.

Putting all the pieces together, the expected loss decreases by almost 2 standard deviations when $\delta$ drops to 0 from 0.2 . This finding may explain why indexation clauses have disappeared in most countries and why the OECD is recommending Belgium and Luxembourg to reduce their degree of indexation.

\section{Two-country setup}

Let us assume two economies. The only difference between them is their degree of indexation. The degree of indexation of the country one is $\delta_{1} \in[0,1]$ while the degree of indexation of the country two is $\delta_{2} \in[0,1]$ and $\delta_{1} \neq \delta_{2}$. 
In this section, the assumptions are exactly the same than the ones proposed at the very beginning of the section 2. To clarify and to keep things as simple as possible, let us remember that there is a continuum of households between 0 and 1 . One half of them lives in country one and the other half lives in country two. They live for two periods following an overlapping generations scheme, with the same number of newborns in each country during each period. There is no population growth.

Turning the attention to the firms, there is a continuum between 0 and 1 . One half of them is settled at country one and the other half at country two. There is no mobility of either workers or firms across the two countries. All the goods are tradeables and imperfect substitutes. The elasticity of substitution between goods is $\varepsilon$. The exchange rate is fixed (as in the Euro area). This setup implies the same level of aggregate price index across countries. Firms (and workers) settled in each country are divided into two sectors.

The workers set their wage when they are born. The labour contract lasts for two periods (during all the worker's life) and the wage during the second period of the contract depends on the indexation to lagged inflation clauses. Finally, there is a monetary authority that is able to control the nominal interest rate to minimise the central bank's expected loss.

The timing of the model does not change and the consumption decision remains as in section 2. The household's demand of each variety, no matter where it is produced, may be expressed by,

$$
V_{i j}=\left(\frac{P_{j}}{P}\right)^{-\varepsilon} C_{i}
$$

where,

$$
C_{i}=\left[\int_{0}^{1} V_{i j}^{\frac{1}{\mu}} d j\right]^{\mu}
$$

and $C_{i}$ is (in a context without uncertainty),

$$
C_{i t}=\frac{\beta^{t}}{\left(1+\lambda_{m}\right)(1+\beta) P_{t}}\left[\sum_{j=0}^{1}\left(\frac{1}{1+r_{0}}\right)^{j}\left[W_{i j} N_{i j}+\Pi_{j}\right]\right]
$$


Aggregate consumption is defined as follows,

$$
C_{t}=\int_{0}^{1} C_{i t} d i
$$

The price-setting decision does not change: price is set as a mark-up over the marginal cost,

$$
P_{j}=\frac{\varepsilon}{\varepsilon-1} W_{j}=\mu W_{j}
$$

As a matter of fact, the only difference across the two countries will be found in the wage-setting equation because the degree of indexation is different from one country to another. A household that is just born in country 1 solves the following problem

$$
\begin{gathered}
\begin{array}{c}
\operatorname{Max} \\
\left\{W_{i 0}^{1}\right\}
\end{array} \sum_{t=0}^{1} \beta^{k}\left[\log C_{i t}+\lambda_{m} \log \frac{M_{i t}}{P_{t}}-\lambda_{n} N_{i t}\right] \\
\text { s.t. } C_{i t}=\frac{\beta^{t}}{\left(1+\lambda_{m}\right)(1+\beta) P_{t}}\left[\sum_{j=0}^{1}\left(\frac{1}{1+r}\right)^{j}\left[W_{i j} N_{i j}+\Pi_{j}\right]\right] \\
\frac{M_{i 0}}{P_{0}}=\lambda_{m}\left(1-\frac{1}{1+r}\right)^{-1} C_{i 0} \\
\frac{M_{i 1}}{P_{1}}=\lambda_{m}\left(\frac{1}{1+r}\right)^{-1} C_{i 1} \\
N_{i t}=\left[\frac{\mu W_{i t}}{P_{t}}\right]^{-\varepsilon} C_{t} \\
\Pi_{t}=\frac{1}{\varepsilon} P_{t} C_{t} \\
W_{i 1}=W_{i 0}\left(1+\delta_{1} \pi_{0}\right)
\end{gathered}
$$

And the log-linearized wage-setting equation can be written as follows,

$$
\begin{aligned}
\widehat{w}_{s 0}^{1}= & \frac{\beta \delta_{1}\left(\varepsilon^{2} \lambda_{n}+(1-\varepsilon)\right)}{\left(\varepsilon^{2} \lambda_{n}(\mu+\beta)+(1+\beta)(1-\varepsilon)\right)} \widehat{p}_{-1} \\
& +\frac{\varepsilon^{2} \lambda_{n} \mu+(1-\varepsilon)-\beta \delta_{1}\left(\varepsilon^{2} \lambda_{n}+(1-\varepsilon)\right)}{\left(\varepsilon^{2} \lambda_{n}(\mu+\beta)+(1+\beta)(1-\varepsilon)\right)} \widehat{p}_{0}+ \\
& +\frac{\beta\left(\varepsilon^{2} \lambda_{n}+(1-\varepsilon)\right)}{\left(\varepsilon^{2} \lambda_{n}(\mu+\beta)+(1+\beta)(1-\varepsilon)\right)} \widehat{p}_{1} \\
& +\frac{\varepsilon \lambda_{n}}{\left(\varepsilon^{2} \lambda_{n}(\mu+\beta)+(1+\beta)(1-\varepsilon)\right)}\left(\widehat{c}_{0}+\beta \widehat{c}_{1}\right)
\end{aligned}
$$


where $\widehat{w}_{s 0}^{1}$ denotes the wage set at period $t=0$ by the households working for the firms belonging to the sector $s$ in the country 1 . At the same time a household that is just born in the country 2 solves the same problem, but replacing $\delta_{1}$ with $\delta_{2}$. It can be easily noticed that the inflation equation for the two countries as a whole is exactly the same than the Phillips curve derived in the section 2 with a degree of indexation equal to the average of the degrees of indexation across the different countries,

$$
\pi_{t}^{\text {area }}=\rho_{1} \pi_{t-1}^{\text {area }}+\rho_{2} \pi_{t+1}^{\text {area }}+\rho_{3} \widehat{c}_{t-1}^{\text {area }}+\rho_{4} \widehat{c}_{t}^{\text {area }}+\rho_{5} \widehat{c}_{t+1}^{\text {area }}
$$

where

$$
\begin{aligned}
& \rho_{1}=\rho_{0}^{-1}\left[\frac{1}{2}\left(1+\frac{\varpi_{3}}{\varpi_{2}+\frac{\varpi_{3} \bar{\delta}}{2}}\right) \varpi_{1}+\frac{\bar{\delta}}{2}\right] \\
& \rho_{2}=\rho_{0}^{-1}\left[\frac{1}{2}\left(1+\frac{\varpi_{3}}{\varpi_{2}+\frac{\varpi_{3} \bar{\delta}}{2}}\right) \varpi_{3}\right] \\
& \rho_{3}=\rho_{0}^{-1}\left[1+\frac{\varpi_{3}}{\varpi_{2}+\frac{\varpi_{3} \bar{\delta}}{2}} \varpi_{4}-\frac{1}{2}\left(\frac{\left(\varpi_{1}-\frac{\bar{\delta}_{3}}{2}\right) \varpi_{4}}{\frac{\varpi_{2}}{2}+\frac{\varpi_{3} \bar{\delta}}{4}}\right)+\frac{\varpi_{4}}{2}\right] \\
& \rho_{4}=\rho_{0}^{-1}\left[\frac{1}{2}\left(1+\frac{\varpi_{3}}{\varpi_{2}+\frac{\varpi_{3} \bar{\delta}}{2}}\right)\left(\varpi_{4}-\varpi_{5}\right)-\frac{1}{2}\left(\frac{\left(\varpi_{1}-\frac{\bar{\delta}_{3}}{2}\right) \varpi_{5}}{\frac{\varpi_{2}}{2}+\frac{\varpi_{3} \bar{\delta}}{4}}\right)+\frac{\varpi_{5}}{2}\right] \\
& \rho_{5}=\rho_{0}^{-1}\left[\frac{1}{2}\left(1+\frac{\varpi_{3}}{\varpi_{2}+\frac{\varpi_{3} \bar{\delta}}{2}}\right) \varpi_{5}\right]
\end{aligned}
$$

and

$$
\begin{gathered}
\rho_{0}=1-\frac{1}{2}\left(1+\frac{\varpi_{3}}{\varpi_{2}+\frac{\varpi_{3} \bar{\delta}}{2}}\right) \varpi_{2}+\frac{1}{2}\left(\frac{\left(\varpi_{1}-\frac{\bar{\delta}_{3}}{2}\right) \varpi_{3}}{\frac{\varpi_{2}}{2}+\frac{\varpi_{3} \bar{\delta}}{4}}\right) \varpi_{1} \\
\bar{\delta}=a \delta_{1}+(1-a) \delta_{2}
\end{gathered}
$$

$a$ is the proportion of the population (or the firms) that lives in country 1 . This finding has an implication for the monetary policy analysis: in a simple setting like the one presented here, the optimal common monetary policy for a set of countries exhibiting different degrees of indexation is equal to the 
optimal monetary policy for one country with a degree of indexation equal to the weighted average of the different degrees of indexation.

As an example, let us consider one country with a low degree of indexation $\left(\delta_{1}=0.02\right)$ and another country with a higher degree of indexation $\left(\delta_{2}=0.2\right)$. The optimal monetary policy rule for country 1 can be expressed by

$$
r_{t}^{1}=0.027 \pi_{t}
$$

while the optimal rule for country 2 is

$$
r_{t}^{2}=0.291 \pi_{t}
$$

If both countries were to share their monetary policy actions and the assumptions stated above hold, the optimal monetary policy for the whole area would be (for $a=0.5$ )

$$
r_{t}^{\text {area }}=0.156 \pi_{t}
$$

What are the implied losses of setting a common monetary policy? Table 2 presents the losses for these two countries when they are able to decide their own monetary policy actions and when they decide to establish a common monetary policy framework. The increase in expected losses in the non-indexed country is $39 \%$ higher than the one in the indexed country. It is fair to say that looking to this particular point may be misleading, because to set a common monetary policy has many other benefits and drawbacks, but it seems that the non-indexed countries may suffer the worst consequences of a more active monetary policy. Moreover, the expected loss of delegating the monetary policy is minimised if the degrees of indexation of all countries were the same (in particular, the global optimum of this model is reached if the degree of indexation of all countries is set equal to zero). 


\section{Conclusions}

In this paper, I present a simple model that can explain the empirical dependence of the current inflation rate on past inflation rates. The key feature of this model is the existence of indexation clauses in the labour contracts linking future wage changes to the lagged observed inflation rate. The main conclusion that can be drawn using this model is that the higher the proportion of labour contracts that include these indexation clauses, the more important the past inflation rate will be when trying to explain current inflation developments.

It is fair to say that the relevance of this type of indexed labour contracts has decreased during the 1990s, but they still remain valid in some countries and are recognised as being a widespread way of indexing wages. Moreover, some authors have suggested that the degree of indexation is underestimated, given that there is a so-called implicit form of indexation. If this model is felt to give a fairly accurate reflection of reality, it could be used to estimate a the overall degree of indexation. However, this simple model alone is not capable of explaining a relatively large inflation autocorrelation coefficient relying only on a small degree of indexation. In other words, wage indexation to lagged inflation may play a role in inflation dynamics, but it does not seem to be the most important factor.

Welfare analysis reveals that the optimal monetary actions are consistent with stronger reactions of the nominal interest rate to inflation expectation changes when the degree of indexation is higher. This model also supports the optimality of non-indexed wages.

Where a monetary union is concerned, the expected loss that each country assumes when delegating its monetary policy decisions will be minimised if all countries exhibit similar degrees of indexation. Indeed, the first best outcome is achieved when all indexation clauses are removed. 


\section{A Log-linearizing the first order condition of the wage setting problem.}

The first order condition of the wage-setting problem is given by

$$
\begin{aligned}
& -\left[\begin{array}{c}
\left(\frac{W_{i 0}}{P_{0}}\left[\frac{\mu W_{i 0}}{P_{0}}\right]^{-\varepsilon}+\frac{1}{\varepsilon}\right) C_{0} \\
+\frac{1}{1+r_{0}}\left(\frac{W_{i 0}\left(1+\delta \pi_{0}\right)}{P_{0}}\left[\frac{\mu W_{i 0}\left(1+\delta \pi_{0}\right)}{P_{1}}\right]^{-\varepsilon}+\frac{1}{\varepsilon}\right) C_{1}
\end{array}\right]^{-1} \\
& (\varepsilon-1)(1+\beta)\left(1+\lambda_{m}\right)\left(\left(\frac{W_{i 0}}{P_{0}}\right)^{1-\varepsilon}+\beta\left(1+\delta \pi_{0}\right)^{1-\varepsilon} \frac{W_{i 0}}{P_{0}}\left(\frac{W_{i 0}}{P_{1}}\right)^{\varepsilon}\right) \\
& +\varepsilon \lambda_{n}\left[C_{0}\left(\frac{W_{i 0}}{P_{0}}\right)^{-\varepsilon}+\beta C_{1}\left(\frac{W_{i 0}\left(1+\delta \pi_{0}\right)}{P_{1}}\right)^{-\varepsilon}\right]=0
\end{aligned}
$$

The following auxiliary function is defined,

$$
\begin{gathered}
F\left(w_{i 0}, p_{0}, p_{1}, r_{0}, c_{0}, c_{1}, \pi_{0}\right)= \\
-\left[\begin{array}{c}
\left(\mu^{-\varepsilon}\left(e^{\left(w_{i 0}-p_{0}\right)}\right)^{1-\varepsilon}+\frac{1}{\varepsilon}\right) e^{c_{0}} \\
+e^{-r_{0}}\left(\left(e^{\delta \pi_{0}}\right)^{1-\varepsilon} \mu^{-\varepsilon} e^{\left(w_{i 0}-p_{0}\right)}\left(e^{\left(w_{i 0}-p_{1}\right)}\right)^{-\varepsilon}+\frac{1}{\varepsilon}\right) e^{c_{1}}
\end{array}\right]^{-1} \\
(\varepsilon-1)(1+\beta)\left(1+\lambda_{m}\right)\left(\left(e^{\left(w_{i 0}-p_{0}\right)}\right)^{1-\varepsilon}+\beta\left(e^{\delta \pi_{0}}\right)^{1-\varepsilon} e^{\left(w_{i 0}-p_{0}\right)}\left(e^{\left(w_{i 0}-p_{1}\right)}\right)^{-\varepsilon}\right) \\
+\varepsilon \lambda_{n}\left[e^{c_{o}}\left(e^{\left(w_{i 0}-p_{0}\right)}\right)^{-\varepsilon}+\beta e^{c_{1}}\left(e^{\delta \pi_{0}}\right)^{-\varepsilon}\left(e^{\left(w_{i 0}-p_{1}\right)}\right)^{-\varepsilon}\right]
\end{gathered}
$$

where a lowercase variable represents the logarithm of the uppercase variable and the following approximation has been made, valid for small $\pi_{0}$ and $r_{0}$,

$$
\begin{aligned}
\log \left(1+\delta \pi_{0}\right) & \simeq \delta \pi_{0} \\
\log \left(\frac{1}{1+r_{0}}\right) & \simeq-r_{0}
\end{aligned}
$$

The objective of this section is to calculate this functional form,

$$
\begin{gathered}
F_{e q}+\frac{\partial F}{\partial w_{i 0}}\left(w_{i 0}-w^{*}\right)+\frac{\partial F}{\partial c_{0}}\left(c_{0}-c^{*}\right)+\frac{\partial F}{\partial c_{t+1}}\left(c_{1}-c^{*}\right)+ \\
+\frac{\partial F}{\partial p_{0}}\left(p_{0}-p^{*}\right)+\frac{\partial F}{\partial p_{1}}\left(p_{1}-p^{*}\right)+\frac{\partial F}{\partial \pi_{0}} \pi_{0}+\frac{\partial F}{\partial r_{0}} r_{0}=0
\end{gathered}
$$


Evaluating the derivatives at the zero-inflation equilibrium yields,

$$
\begin{aligned}
\frac{\partial F}{\partial w_{i 0}} & =-\left(\varepsilon^{2} \lambda_{n}(\mu+\beta)+(1+\beta)(1-\varepsilon)\right) \frac{\left(1+\lambda_{m}\right)}{\mu^{2}} \\
\frac{\partial F}{\partial p_{0}} & =\left(\varepsilon^{2} \lambda_{n} \mu+(1-\varepsilon)\right) \frac{\left(1+\lambda_{m}\right)}{\mu^{2}} \\
\frac{\partial F}{\partial p_{1}} & =\beta\left(\varepsilon^{2} \lambda_{n}+(1-\varepsilon)\right) \frac{\left(1+\lambda_{m}\right)}{\mu^{2}} \\
\frac{\partial F}{\partial \pi_{0}} & =-\beta \delta\left(\varepsilon^{2} \lambda_{n}+(1-\varepsilon)\right) \frac{\left(1+\lambda_{m}\right)}{\mu^{2}} \\
\frac{\partial F}{\partial c_{0}} & =\varepsilon \lambda_{n} C^{*} \\
\frac{\partial F}{\partial c_{1}} & =\beta \varepsilon \lambda_{n} C^{*} \\
\frac{\partial F}{\partial r_{0}} & =0
\end{aligned}
$$

Thus, the log-linearized first order condition may be written as follows

$$
\begin{aligned}
\widehat{w}_{i 0}= & \frac{\varepsilon^{2} \lambda_{n} \mu+(1-\varepsilon)}{\left(\varepsilon^{2} \lambda_{n}(\mu+\beta)+(1+\beta)(1-\varepsilon)\right)} \widehat{p}_{0} \\
& +\frac{\beta\left(\varepsilon^{2} \lambda_{n}+(1-\varepsilon)\right)}{\left(\varepsilon^{2} \lambda_{n}(\mu+\beta)+(1+\beta)(1-\varepsilon)\right)} \widehat{p}_{1} \\
& -\frac{\beta \delta\left(\varepsilon^{2} \lambda_{n}+(1-\varepsilon)\right)}{\left(\varepsilon^{2} \lambda_{n}(\mu+\beta)+(1+\beta)(1-\varepsilon)\right)} \pi_{0} \\
& +\frac{\varepsilon \lambda_{n}}{\left(\varepsilon^{2} \lambda_{n}(\mu+\beta)+(1+\beta)(1-\varepsilon)\right)}\left(\widehat{c}_{0}+\beta \widehat{c}_{1}\right)
\end{aligned}
$$




\section{B Derivation of inflation equation}

The aggregate price index is driven by this expression,

$$
\begin{aligned}
p_{t} & =\frac{1}{2}\left[\widehat{w}_{1 t}+\widehat{w}_{2 t}\right] \\
p_{t+1} & =\frac{1}{2}\left[\widehat{w}_{1 t+1}+\widehat{w}_{2 t+1}\right]=\frac{1}{2}\left[\widehat{w}_{1 t}+\delta \pi_{t}+\widehat{w}_{2 t+1}\right]= \\
& =\frac{1}{2}\left[\widehat{w}_{1 t}+\delta \widehat{p}_{t}-\delta \widehat{p}_{t-1}+\widehat{w}_{2 t+1}\right]= \\
& =\frac{1}{2}\left[\widehat{w}_{1 t}+\frac{\delta}{2}\left[\widehat{w}_{1 t}+\widehat{w}_{2 t}\right]-\delta \widehat{p}_{t-1}+\widehat{w}_{2 t+1}\right]= \\
& =\frac{1}{2}\left[\left(1+\frac{\delta}{2}\right) \widehat{w}_{1 t}+\frac{\delta}{2} \widehat{w}_{2 t}-\delta \widehat{p}_{t-1}+\widehat{w}_{2 t+1}\right]
\end{aligned}
$$

The inflation rate may be approximated by

$$
\begin{aligned}
\pi_{t} & \simeq \widehat{p}_{t}-\widehat{p}_{t-1}=\frac{1}{2}\left[\widehat{w}_{1 t}+\widehat{w}_{2 t}\right]-\frac{1}{2}\left[\widehat{w}_{1 t-1}+\widehat{w}_{2 t-1}\right]= \\
& =\frac{1}{2}\left[\Delta \widehat{w}_{1 t}+\Delta \widehat{w}_{2 t}\right]=\frac{1}{2}\left[\widehat{w}_{1 t}-\widehat{w}_{1 t-1}+\delta \pi_{t-1}\right]
\end{aligned}
$$

and the wage-setting equation is,

$$
\widehat{w}_{1 t}=\varpi_{1} \widehat{p}_{t-1}+\varpi_{2} \widehat{p}_{t}+\varpi_{3} \widehat{p}_{t+1}+\varpi_{4} \widehat{c}_{t}+\varpi_{5} \widehat{c}_{t+1}
$$

Substituting the aggregate price formulas into the wage-setting equation and reordering yields,

$$
\begin{aligned}
\widehat{w}_{1 t}= & {\left[1-\frac{\varpi_{2}}{2}-\frac{\varpi_{3}}{2}\left(1+\frac{\delta}{2}\right)\right]^{-1} } \\
& {\left[\left(\varpi_{1}-\frac{\delta \varpi_{3}}{2}\right) \widehat{p}_{t-1}+\frac{1}{2}\left(\varpi_{2}+\frac{\varpi_{3} \delta}{2}\right) \widehat{w}_{2 t}+\frac{\varpi_{3}}{2} \widehat{w}_{2 t+1}+\varpi_{4} \widehat{c}_{t}+\varpi_{5} \widehat{c}_{t+1}\right] }
\end{aligned}
$$

Sector 2 negotiates at period $t-1$. So, its wage-setting equation is,

$$
\begin{aligned}
\widehat{w}_{2 t-1}= & {\left[1-\frac{\varpi_{2}}{2}-\frac{\varpi_{3}}{2}\left(1+\frac{\delta}{2}\right)\right]^{-1} } \\
& {\left[\left(\varpi_{1}-\frac{\delta \varpi_{3}}{2}\right) \widehat{p}_{t-2}+\frac{1}{2}\left(\varpi_{2}+\frac{\varpi_{3} \delta}{2}\right) \widehat{w}_{1 t-1}+\frac{\varpi_{3}}{2} \widehat{w}_{1 t}+\varpi_{4} \widehat{c}_{t-1}+\varpi_{5} \widehat{c}_{t}\right] }
\end{aligned}
$$


Solving for $\widehat{w}_{1 t-1}$ and substituting this expression into the inflation equation,

$$
\begin{aligned}
\pi_{t}= & \frac{1}{2}\left(1+\frac{2 \varpi_{3}}{2 \varpi_{2}+\varpi_{3} \delta}\right)\left(\widehat{w}_{1 t}-\widehat{w}_{2 t-1}\right)-\left(\frac{2 \varpi_{1}-\delta \varpi_{3}}{2 \varpi_{2}+\varpi_{3} \delta}\right)\left(\widehat{w}_{2 t-1}-\widehat{p}_{t-2}\right)+ \\
& +\frac{2 \varpi_{4}}{2 \varpi_{2}+\varpi_{3} \delta} \widehat{c}_{t-1}+\frac{2 \varpi_{5}}{2 \varpi_{2}+\varpi_{3} \delta} \widehat{c}_{t}
\end{aligned}
$$

To obtain expressions for $\widehat{w}_{1 t}-\widehat{w}_{2 t-1}$ and $\widehat{w}_{2 t-1}-\widehat{p}_{t-2}$ is far from difficult. From the wage- setting equation at time $t$ and $t-1$, it may be obtained that,

$$
\widehat{w}_{1 t}-\widehat{w}_{2 t-1}=\varpi_{1} \pi_{t-1}+\varpi_{2} \pi_{t}+\varpi_{3} \pi_{t+1}+\varpi_{4} \Delta \widehat{c}_{t}+\varpi_{5} \Delta \widehat{c}_{t+1}
$$

and from the wage-setting equation at time $t-1$,

$$
\begin{aligned}
\widehat{w}_{2 t-1}-\widehat{p}_{t-2} & =\left(\varpi_{1}-1\right) \widehat{p}_{t-2}+\varpi_{2} \widehat{p}_{t-1}+\varpi_{3} \widehat{p}_{t}+\varpi_{4} \widehat{c}_{t-1}+\varpi_{5} \widehat{c}_{t}= \\
& =\left(\varpi_{2}+\varpi_{3}\right) \pi_{t-1}+\varpi_{3} \pi_{t}+\varpi_{4} \widehat{c}_{t-1}+\varpi_{5} \widehat{c}_{t}
\end{aligned}
$$

Substituting these expressions into the inflation equation and solving for $\pi_{t}$ yields,

$$
\pi_{t}=\rho_{1} \pi_{t-1}+\rho_{2} \pi_{t+1}+\rho_{3} \widehat{c}_{t-1}+\rho_{4} \widehat{c}_{t}+\rho_{5} \widehat{c}_{t+1}
$$

where

$$
\begin{aligned}
& \rho_{1}=\rho_{0}^{-1}\left[\frac{1}{2}\left(1+\frac{2 \varpi_{3}}{2 \varpi_{2}+\varpi_{3} \delta}\right) \varpi_{1}+\frac{\delta}{2}\right] \\
& \rho_{2}=\rho_{0}^{-1}\left[\frac{1}{2}\left(1+\frac{2 \varpi_{3}}{2 \varpi_{2}+\varpi_{3} \delta}\right) \varpi_{3}\right] \\
& \rho_{3}=\rho_{0}^{-1}\left[1+\frac{2 \varpi_{3}}{2 \varpi_{2}+\varpi_{3} \delta} \varpi_{4}-\frac{\left(2 \varpi_{1}-\delta \varpi_{3}\right) \varpi_{4}}{2 \varpi_{2}+\varpi_{3} \delta}+\frac{\varpi_{4}}{2}\right] \\
& \rho_{4}=\rho_{0}^{-1}\left[\frac{1}{2}\left(1+\frac{2 \varpi_{3}}{2 \varpi_{2}+\varpi_{3} \delta}\right)\left(\varpi_{4}-\varpi_{5}\right)-\frac{\left(2 \varpi_{1}-\delta \varpi_{3}\right) \varpi_{5}}{2 \varpi_{2}+\varpi_{3} \delta}+\frac{\varpi_{5}}{2}\right] \\
& \rho_{5}=\rho_{0}^{-1}\left[\frac{1}{2}\left(1+\frac{2 \varpi_{3}}{2 \varpi_{2}+\varpi_{3} \delta}\right) \varpi_{5}\right]
\end{aligned}
$$

and

$$
\rho_{0}=1-\frac{1}{2}\left(1+\frac{2 \varpi_{3}}{2 \varpi_{2}+\varpi_{3} \delta}\right) \varpi_{2}+\frac{\left(2 \varpi_{1}-\delta \varpi_{3}\right) \varpi_{3}}{2 \varpi_{2}+\varpi_{3} \delta} \varpi_{1}
$$




\section{Reduced-form solutions}

This appendix builds close on Christiano (2001). As it was mentioned above, the Minimal State Variable procedure is being used here. There is only one state variable in the system, the inflation rate, because the output gap can be calculated using an unknown mapping function going from $\pi_{t}$ to $\widehat{c}_{t}=f\left(\pi_{t}\right)$. Following Christiano (2001), let us define the vector of endogenous variables as,

$$
z_{1 t}=\left[\begin{array}{c}
\pi_{t} \\
\widehat{c}_{t}
\end{array}\right]
$$

and $z_{2 t}=z_{1 t-1}$. Defining $z_{t}=\left[\left(z_{1 t}\right)^{\prime}\left(z_{2 t}\right)^{\prime}\right]^{\prime}$, the system of the structural equations may be written as

$$
\begin{gathered}
\xi_{t}\left[\begin{array}{cccc}
-\rho_{2} & -\rho_{5} & 0 & 0 \\
-\sigma & -1 & 0 & 0
\end{array}\right] z_{t+1}+\xi_{t}\left[\begin{array}{cccc}
1 & -\rho_{4} & 0 & 0 \\
0 & 1 & 0 & 0
\end{array}\right] z_{t}+ \\
+\xi_{t}\left[\begin{array}{cccc}
-\rho_{1} & -\rho_{3} & 0 & 0 \\
0 & 0 & 0 & 0
\end{array}\right] z_{t-1}+\xi_{t}\left[\begin{array}{c}
-1 \\
0
\end{array}\right] s_{t}=0
\end{gathered}
$$

where $\xi_{t}$ denotes the expectations operator with respect to an information set that may differ across equations (as it happens in this model). This procedure seeks to calculate matrices $A$ and $B$ that must define the law of motion of the model,

$$
z_{t}=A z_{t-1}+B s_{t}
$$

So, let us denote

$$
A=\left[\begin{array}{l}
A_{1} \\
A_{2}
\end{array}\right]
$$

where $A_{1}$ is a $2 \times 4$ matrix of undetermined coefficients and

$$
A_{2}=\left[\begin{array}{llll}
1 & 0 & 0 & 0 \\
0 & 1 & 0 & 0
\end{array}\right]
$$


To calculate $A_{1}$ (called by Christiano as the feedback component), it is useful to start from the system

$$
a Y_{t+1}+b Y_{t}=0, \quad t \geq 0
$$

where $Y_{t}=\left[\begin{array}{ll}z_{1 t}^{\prime} & z_{t-1}^{\prime}\end{array}\right]^{\prime}$, and the matrices $a$ and $b$ are defined as follows,

$$
\begin{aligned}
a & =\left[\begin{array}{cccccc}
-\rho_{2} & -\rho_{5} & 0 & 0 & 0 & 0 \\
-\sigma & -1 & 0 & 0 & 0 & 0 \\
0 & 0 & 1 & 0 & 0 & 0 \\
0 & 0 & 0 & 1 & 0 & 0 \\
0 & 0 & 0 & 0 & 1 & 0 \\
0 & 0 & 0 & 0 & 0 & 1
\end{array}\right] \\
b= & {\left[\begin{array}{ccccccc}
1 & -\rho_{4} & -\rho_{1} & -\rho_{3} & 0 & 0 \\
0 & 1 & 0 & 0 & 0 & 0 \\
-1 & 0 & 0 & 0 & 0 & 0 \\
0 & -1 & 0 & 0 & 0 & 0 \\
0 & 0 & -1 & 0 & 0 & 0 \\
0 & 0 & 0 & -1 & 0 & 0
\end{array}\right] }
\end{aligned}
$$

In this context, a solution is defined as a sequence $\left\{Y_{t} ; t \geq 0\right\}$ that satisfies the four initial conditions $\left(z_{0}\right)$ and the equation (A.2) at all dates. Given $\pi_{-1}$ and $c_{-1}$ there are two initial free conditions. Each solution is determined by the election of these two initial conditions $\left(\pi_{0}\right.$ and $\left.c_{0}\right)$. Thus, the dimension of the space of solutions is 2. An element of the space of solutions is said to be a Minimal State Variable (MSV) solution if there is a matrix $D$ that satisfies two conditions. First, the square matrix composed by its two first rows and columns should be invertible. And second,

$$
D Y_{t}=0, \quad t \geq 0
$$

An element of the space solution is said to be nonexplosive if $Y_{t} \rightarrow 0$ as $t \rightarrow \infty$ for all possible initial conditions. As the matrix $a$ is invertible, (A.2) 
implies that all solutions can be expressed as

$$
Y_{t}=\left(-a^{-1} b\right)^{t} Y_{0}
$$

Decomposing the matrix $-a^{-1} b$ into $P \Lambda P^{-1}$ (where $\Lambda$ is a diagonal matrix with the eigenvalues of $-a^{-1} b$ placed along the diagonal and $P$ is the associated eigenvector matrix) yields,

$$
P^{-1} Y_{t}=\Lambda^{t} P^{-1} Y_{0}
$$

If the number of roots whose absolute value exceeds 1 is bigger than 2 , there is no stable solution. If this number is 2 , there is one and only one stable, convergent MSV solution. This solution may be obtained by solving the system $\widetilde{p} Y_{0}=0$, where $\widetilde{p}$ is equal to the rows of $P^{-1}$ that are related to the two explosive roots of $\Lambda$. If the number of explosive roots is one, there may be more than one MSV nonexplosive solution. Each solution is determined by the way in which the matrix $\widetilde{p}$ is constructed. It has to include the rows of $P^{-1}$ associated to the explosive root of $\Lambda$ to assure stability. The other row of $\widetilde{p}$ may include any of the rows of $P^{-1}$ related to the nonexplosive roots. So, in this case there may be as many stable MSV solutions as different nonexplosive roots.

Once the free elements of $Y_{0}$ have been determined, $\widetilde{p} Y_{0}=0$ implies $\widetilde{p} Y_{t}=0$ for $t \geq 0$. Then, the $\widetilde{p}$ matrix is the $D$ matrix we were looking for. To obtain $A_{1}$, let us define $D Y_{t} \equiv D^{1} z_{1 t}+D^{2} z_{t-1}=0$. This implies

$$
z_{1 t}=-\left(D^{1}\right)^{-1} D^{2} z_{t-1}=A_{1} z_{t-1}
$$

To calculate the feedforward part of the reduced-form solution (the matrix $B)$ is extremely easy. As expectations in the Phillips curve are taken with respect to the information available at $t-1$, the coefficient of the shock must be 1 . The effect on consumption can be calculated by noting that the feedback part and the Euler equation imply (assuming $r=0$ ),

$$
\widehat{c}_{t}=\frac{A_{1}(2,1)+\sigma A_{1}(1,1)}{1-A_{1}(2,2)-\sigma A_{1}(1,2)} \pi_{t}
$$


Therefore,

$$
B=\left[\begin{array}{c}
1 \\
\frac{A_{1}(2,1)+\sigma A_{1}(1,1)}{1-A_{1}(2,2)-\sigma A_{1}(1,2)}
\end{array}\right]
$$

and the description of the solution is complete. 


\section{References}

[1] Ascari, Guido and Juan A. Garcia (2000), "Relative Wage Concern: the Missing Piece in the Contract Multiplier", mimeo.

[2] Atkeson, Andrew and Lee E. Ohanian (2001), "Are Phillips Curves Useful for Forecasting Inflation?", Federal Reserve Bank of Minneapolis' Quarterly Review, Winter.

[3] Ball, Laurence (1987), "Externalities from Contract Length", American Economic Review 77, pp. 615-629.

[4] Ball, Laurence and Stephen G. Cecchetti (1988), "Imperfect Information and Staggered Price Setting", American Economic Review 78, pp. 9991018.

[5] Ball, Laurence, Gregory Mankiw and David Romer (1988), "The New Keynesian Economics and the Output-Inflation Trade-Off", Brookings Papers on Economic Activity 1, pp. 1-65.

[6] Blanchard, Olivier (1986), "Price Asynchronization and Price Level Inertia", in Inflation, Debt and Indexation, in R. Dornbusch and M. Simonsen (eds.), MIT Press.

[7] Blanchard, Olivier and Nobuhiro Kiyotaki (1987), "Monopolistic Competition and the Effects of Aggregate Demand", American Economic Review 77, pp. 647-666.

[8] Card, David (1990), "Unexpected Inflation, Real Wages and Employment Determinant in Union Contracts", American Economic Review 80, pp. 669-688. 
[9] Chari, Varadarajan V., Patrick J. Kehoe and Ellen McGrattan (2000), "Sticky Price Models of the Business Cycle: Can the Contract Multiplier Solve the Persistence Problem?", Econometrica 68, pp. 1151-1179.

[10] Cho, Jang-Ok, Thomas Cooley and Louis Phaneuf (1997), "The Welfare Costs of Nominal Wage Contracting", Review of Economic Studies 64, pp. $465-484$.

[11] Christiano, Lawrence J. (2001), "Solving Dynamic Equilibrium Models by a Method of Undetermined Coefficients", mimeo, July.

[12] Christiano, Lawrence J., Martin Eichenbaum and Charles Evans (2001), "Nominal Rigidities and the Dynamic Effects of a Shock to Monetary Policy", NBER Working Paper No. 8403.

[13] Cooley, Thomas and Vicenzo Quadrini (1999), "A Neoclassical Model of the Phillips Curve Relation", Journal of Monetary Economics 44, pp. 165-193.

[14] Crowley, Joe (1997), "The Effects of Forward- versus Backward-Looking Wage Indexation on Price Stabilization Programs", IMF Working Paper $\mathrm{WP} / 97 / 38$.

[15] Dib, Ali (2002), "Nominal Rigidities and Monetary Policy in Canada since 1981", Bank of Canada Working Paper 2002-25.

[16] Dolado, Juan J., Jose D. Lopez-Salido and Juan L. Vega (2000), "Unemployment and Inflation Persistence in Spain: Are There Phillips TradeOffs?", Spanish Economic Review 2, pp. 267-291.

[17] Emerson, Michael (1986), "A View of Current European Indexation Experiences", in Inflation, Debt and Indexation, in R. Dornbusch and M. Simonsen (eds.), MIT Press. 
[18] Erceg, Christopher, Dale W. Henderson and Andrew T. Levin (2000), "Optimal Monetary Policy with Staggered Wage and Price Contracts", Journal of Monetary Economics, 46, pp. 281-313.

[19] Fehtke, Gary and Andrew Policano (1986), "Will Wage Setters Ever Stagger Decisions?", Quarterly Journal of Economics 101, pp.867-877.

[20] Fischer, Stanley (1977), "Long-Term Contracts, Rational Expectations and the Optimal Money Supply Rule", Journal of Political Economy 1, pp. 191-205.

[21] Fischer, Stanley (1986), "Wage Indexation and Macroeconomic Stability", in Inflation, Debt and Indexation, in R. Dornbusch and M. Simonsen (eds.), MIT Press.

[22] Fischer, Stanley (1986), "Indexing and Inflation", in Inflation, Debt and Indexation, in R. Dornbusch and M. Simonsen (eds.), MIT Press.

[23] Fuhrer, Jeffrey (1997), "The (Un)Importance of Forward-Looking Behavior in Price Specifications", Journal of Money, Credit and Banking 29.

[24] Fuhrer, Jeffrey and George Moore (1995), "Inflation Persistence", The Quarterly Journal of Economics.

[25] Gali, Jordi (2000), "The Return of the Phillips Curve and Other Recent Developments on Business Cycle Theory", Spanish Economic Review 2, pp. $1-10$.

[26] Gali, Jordi and Mark Gertler (1999), "Inflation dynamics: A Structural Econometric Analysis", Journal of Monetary Economics 44, pp. 195-222.

[27] Gali, Jordi, Mark Gertler and Jose D. Lopez-Salido (2000), "European Inflation Dynamics", European Economic Review 45, pp. 1237-1270. 
[28] Gali, Jordi, Jose D. Lopez-Salido and Javier Valles (2002), "Technology Shocks and Monetary Policy: Assessing the Fed's Performance", mimeo.

[29] Garcia Perea, Pilar and Ramon Gomez (1993), "Aspectos Institucionales del Mercado de Trabajo Español en Comparacion con Otros Paises Comunitarios", Bank of Spain, Boletin Economico, September.

[30] Gray, Jo Anna (1978), "On Indexation and Contract Length", Journal of Political Economy 84, pp. 1-18.

[31] Gray, Jo Anna (1983), "Wage Indexation, Incomplete Information, and the Aggregate Supply Curve", in Inflation, Debt and Indexation, edited by Dornbusch and Simonsen.

[32] Holland, Steven (1988), "The Changing Responsiveness on Wages to Price-Level Shocks: Explicit and Implicit Indexation", Economic Inquiry 26, pp. 265-279.

[33] Holland, Steven (1995), "Inflation and Wage Indexation in the Postwar United States", The Review of Economics and Statistics 77, pp. 172-176.

[34] Jadresic, Esteban (1998), "The Macroeconomic Consequences of Wage Indexation Revisited", IMF Working Paper WP/98/15.

[35] Laséen, Stefan (2000), "Nominal Wage Contracts, Aggregate and FirmSpecific Uncertainty - How High is the Private Gain from Indexation?", Uppsala University Working Paper No. 2000:11.

[36] Mankiw, N. Gregory (2001), "The Inexorable and Mysterious Trade-off Between Inflation and Unemployment", The Economic Journal 111, pp. C45-C61. 
[37] Mankiw, N. Gregory and Ricardo Reis (2001), "Sticky Information versus Sticky Prices: A Proposal to Replace the New Keynesian Phillips Curve", HIER Discussion Paper No. 1922.

[38] McCallum, Bennett T. (1999), "Role of the Minimal State Variable Criterion in Rational Expectations Models", prepared for the conference in honor of Robert P. Flood at the IMF.

[39] Roberts, John M. (1995), "New Keynesian Economics and the Phillips Curve", Journal of Money, Credit and Banking 27.

[40] Roberts, John M. (1997), "Is Inflation Sticky", Journal of Monetary Economics 39, pp. 173-196.

[41] Roberts, John M. (2001), "How Well Does the New Keynesian StickyPrice Model Fit the Data?", mimeo.

[42] Rotemberg, Julio (1982), "Sticky Prices in the United States", Journal of Political Economy 90, pp. 1187-1211.

[43] Sbordone, Argia M. (2001), “An Optimizing Model of US Wage and Price Dynamics", mimeo, December.

[44] Simonsen, Mario Enrique (1983), "Indexation: Current Theory and the Brazilian Experience", in Inflation, Debt and Indexation, in R. Dornbusch and M. Simonsen (eds.), MIT Press.

[45] Taylor, John B. (1979), "Staggered Wage Setting in a Macro Model", American Economic Review 69.

[46] Taylor, John B. (1998), "Staggered Price and Wage Setting in Macroeconomics", NBER Working Paper 6754.

[47] Woglom, Geoffrey (1990), "Systematic Risks and the Theory of Wage Indexation", Journal of Business 63, pp. 217-237. 
Table 1. VAR estimation results (standard errors in parenthesis).

\begin{tabular}{|l|c|c|}
\hline U.S. annual data 1960-2000 & $\pi_{t}$ equation & gap $_{t}$ equation \\
\hline$\pi_{t-1}$ & $\begin{array}{r}0.7177 \\
(0.188)\end{array}$ & $\begin{array}{r}-0.2258 \\
(0.147)\end{array}$ \\
\hline$\pi_{t-2}$ & $\begin{array}{l}0.0485 \\
(0.192)\end{array}$ & $\begin{array}{l}0.0446 \\
(0.150)\end{array}$ \\
\hline gapp $_{t-1}$ & 0.6768 & 0.8158 \\
& $(0.243)$ & $(0.190)$ \\
\hline gap $_{t-2}$ & -0.4696 & -0.3247 \\
& $(0.210)$ & $(0.164)$ \\
\hline constant & 0.0112 & 0.0090 \\
& $(0.007)$ & $(0.005)$ \\
\hline
\end{tabular}

Table 2. Increase in the expected losses generated by setting a monetary union (in output gap standard deviations).

\begin{tabular}{|c|c|c|}
\hline Monetary policy & Country $1\left(\delta_{1}=0.02\right)$ & Country $2\left(\delta_{2}=0.2\right)$ \\
\hline Different & 0 & 0 \\
\hline Common & 0.125 & 0.090 \\
\hline
\end{tabular}




$$
\widehat{w}_{s t}=\varpi_{1} \widehat{p}_{t-1}+\varpi_{2} \widehat{p}_{t}+\varpi_{3} \widehat{p}_{t+1}+\varpi_{4} \widehat{c}_{t}+\varpi_{5} \widehat{c}_{t+1}
$$

wage equation parameters

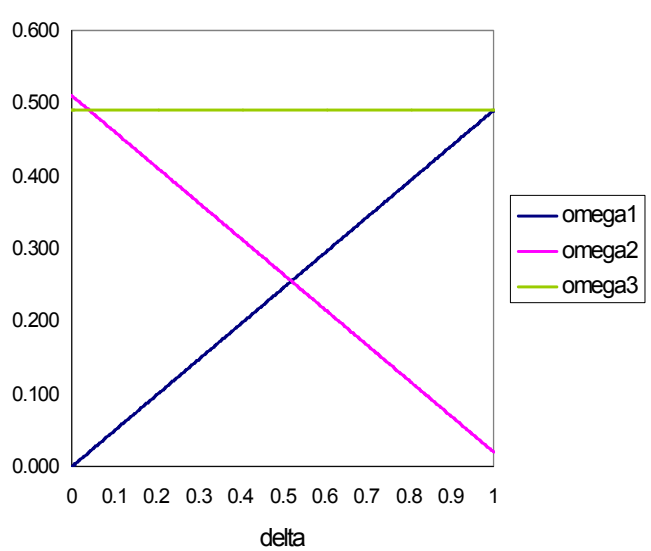

wage equation parameters

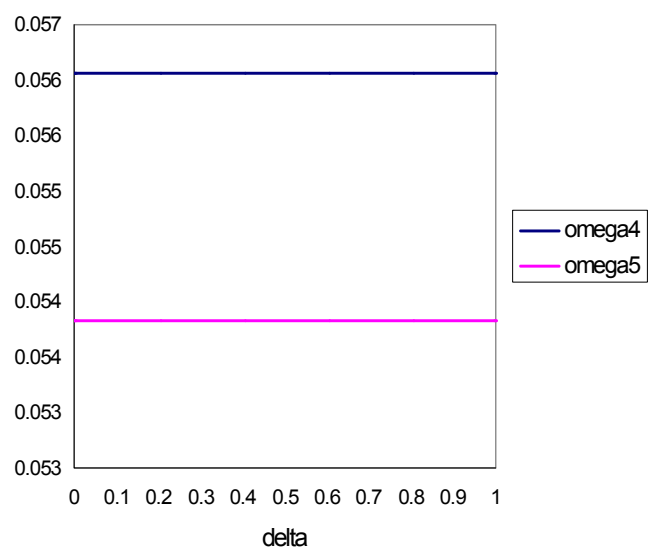

Figure 1: Values of the wage-setting equation parameters when the degree of indexation changes. 


$$
\pi_{t}=\rho_{1} \pi_{t-1}+\rho_{2} \pi_{t+1}+\rho_{3} \widehat{c}_{t+1}+\rho_{4} \widehat{c}_{t}+\rho_{5} \widehat{c}_{t-1}
$$
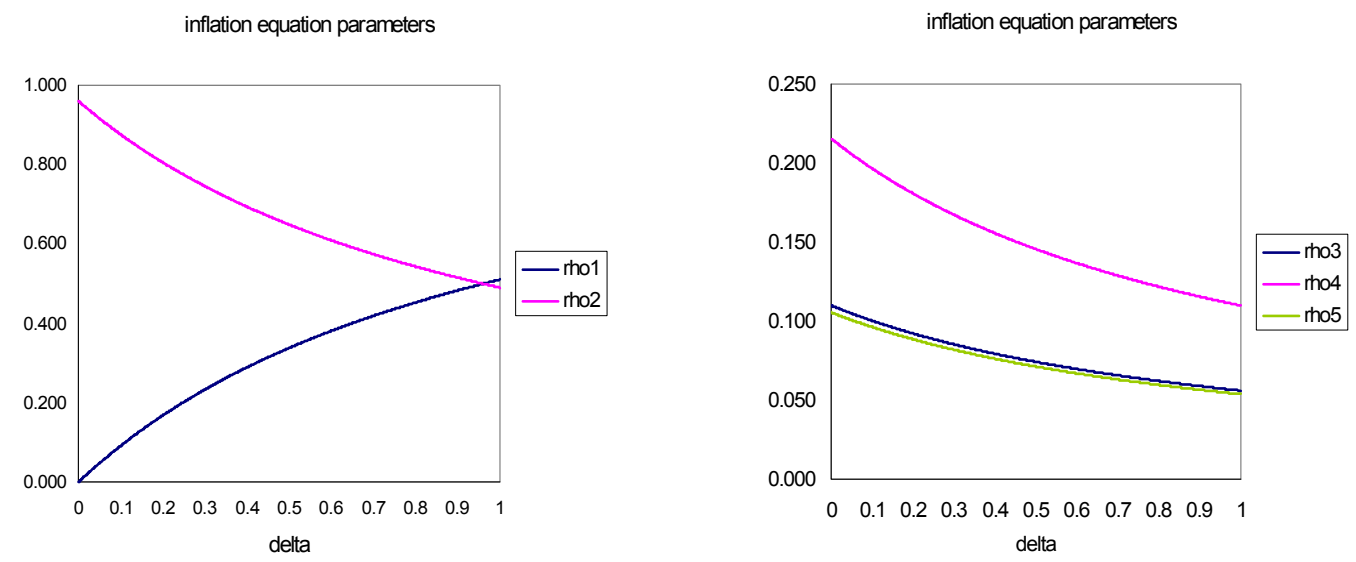

Figure 2: Values of the inflation equation parameters when the degree of indexation changes. 
Response of inflation to an inflation shock

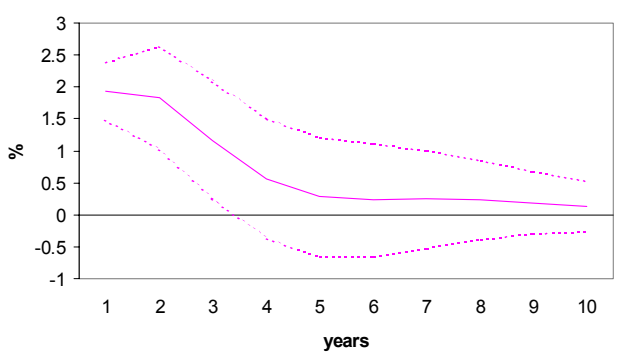

Response of output gap to an inflation shock

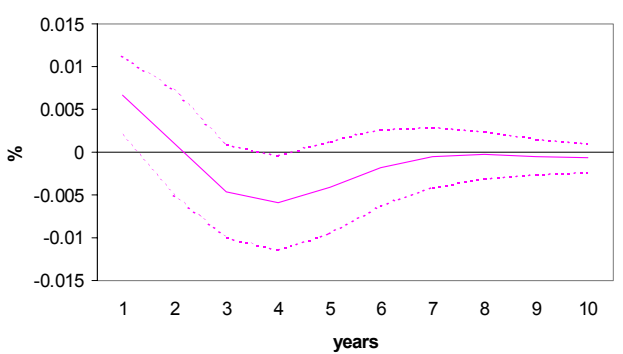

Response of inflation to an output gap shock

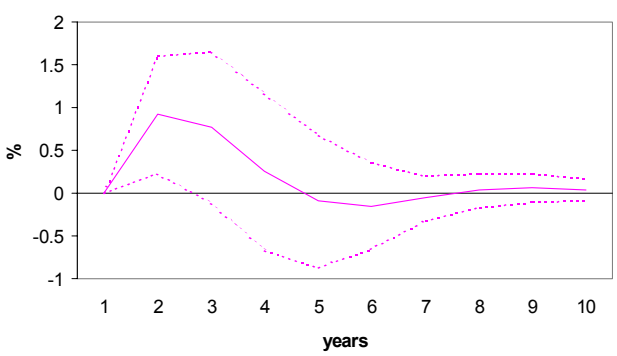

Response of output gap to an output gap shock

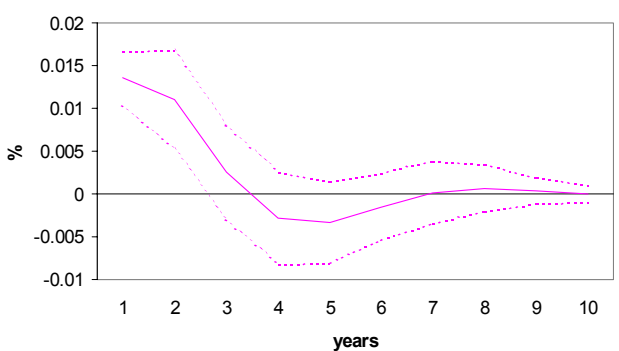

Figure 3: Empirical impulse-response functions (US: 1960-2000). 
Response of Inflation to an inflation shock (delta $=0$ )

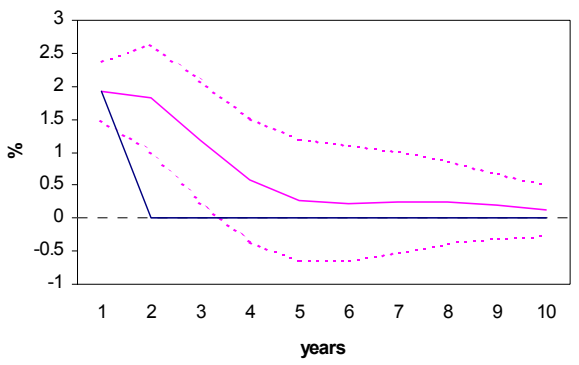

Response of Inflation to an inflation shock (delta $=0.15$ )

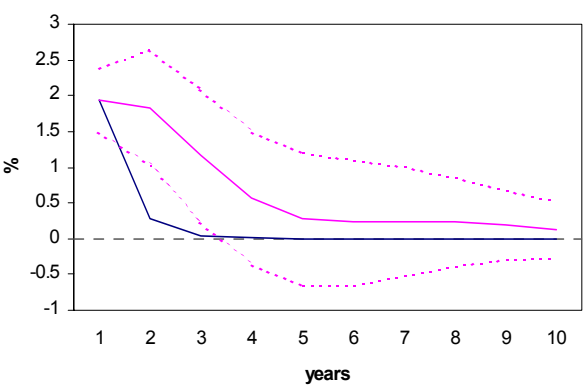

Response of Inflation to an inflation shock (delta=1)

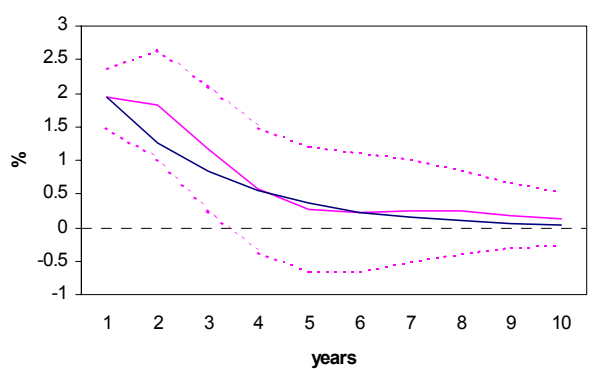

Figure 4: Inflation rate response implied by the model to a macroeconomic shock. 
Inflation autocorrelation

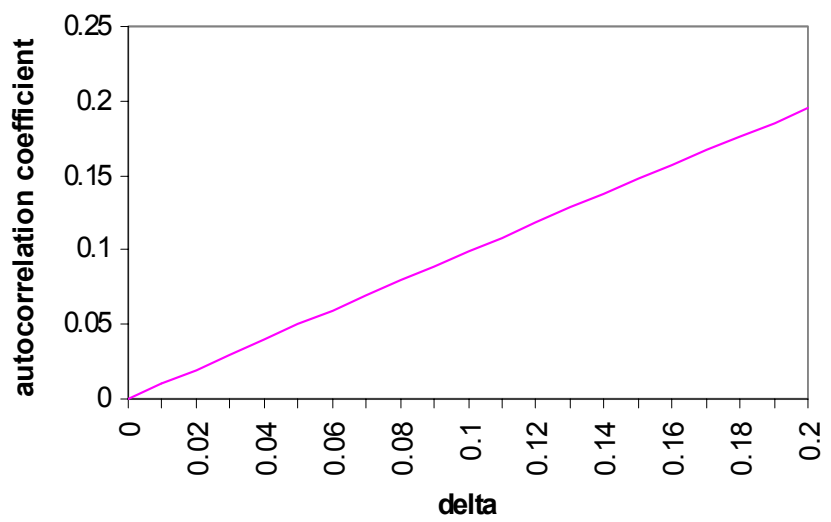

Figure 5: Inflation autocorrelations implied by the model for different degrees of indexation. 


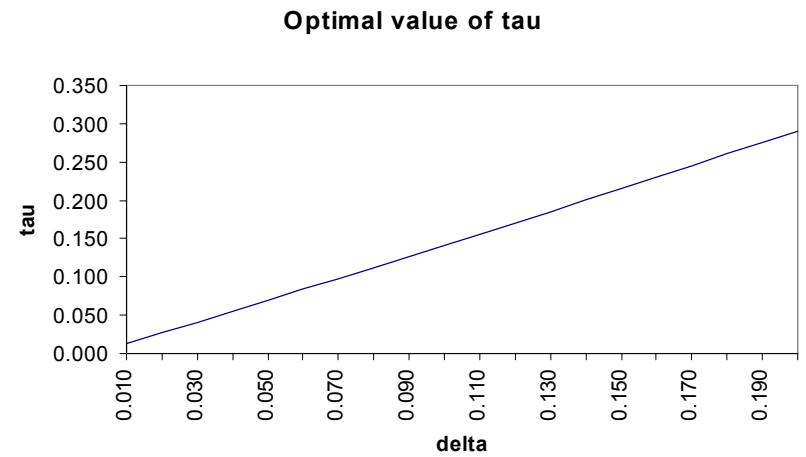

Optimal value of Taylor-based rule parameter

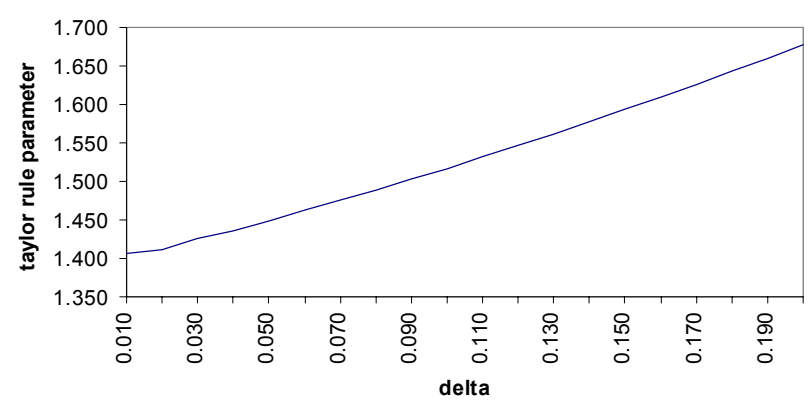

Figure 6: Optimal policy rule parameters for different degrees of indexation. 
Expected losses (in output gap s.d.)

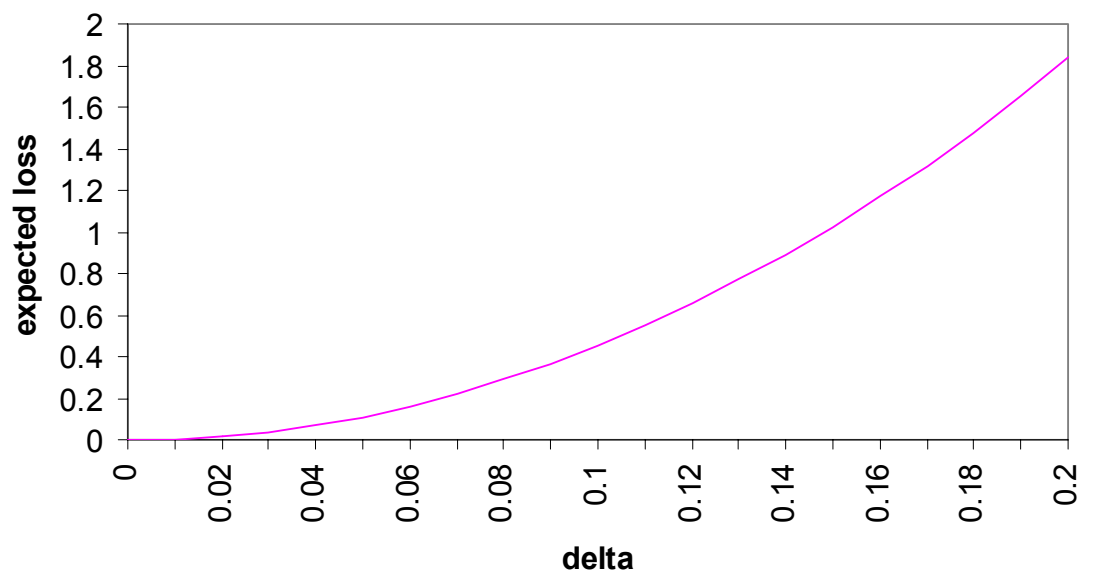

Figure 7: Expected loss (in output gap standard deviations) as a function of the degree of indexation. 